Check for updates

Cite this: Mater. Adv., 2021, 2, 2431

Received 5th November 2020, Accepted 15th February 2021

DOI: $10.1039 / \mathrm{d} 0 \mathrm{ma} 00862 \mathrm{a}$

rsc.li/materials-advances

\title{
Polypyrrole-polyaniline copolymer coated green rice husk ash as an effective adsorbent for the removal of hexavalent chromium from contaminated water $\dagger$
}

\author{
Soumi Dutta, ${ }^{a}$ Suneel Kumar Srivastava (D) *b and Ashok Kumar Gupta*c
}

\begin{abstract}
The acute toxicity and mobility of hexavalent chromium $[\mathrm{Cr}(\mathrm{VI})]$ in water and wastewater pose a severe risk to the environment and human health. In view of this, the present work is focused on the fabrication and characterization of polypyrrole-polyaniline coated rice husk ash (termed as PPYPANIaRHA) by in situ polymerization and its application as an adsorbent in the removal of $\mathrm{Cr}(\mathrm{VI})$ from the aqueous solution. Our findings have shown a $\mathrm{Cr}(\mathrm{VI})$ removal rate of $\sim 98 \%$ at room temperature (303 K) under optimum conditions with an adsorbent dose of $0.8 \mathrm{~g} \mathrm{~L}^{-1}$, an adsorbate concentration of $50 \mathrm{mg} \mathrm{L}^{-1}$, a solution $\mathrm{pH}$ of $\sim 2$, and a contact time of $300 \mathrm{~min}$. The adsorption of $\mathrm{Cr}(\mathrm{vl})$ followed the Elovich kinetics and is better described using the Freundlich isotherm with a maximum adsorption capacity of $769.15 \mathrm{mg} \mathrm{g}^{-1}$. The co-existing ion study result shows that the $\mathrm{Cr}(\mathrm{VI})$ removal efficiency is slightly decreased in the presence of high concentrations of $\mathrm{Na}^{+}, \mathrm{Mg}^{2+}, \mathrm{Ca}^{2+}, \mathrm{Cl}^{-}, \mathrm{HCO}_{3}{ }^{-}, \mathrm{NO}_{3}{ }^{-}, \mathrm{SO}_{4}{ }^{2-}$ and $\mathrm{PO}_{4}{ }^{3-}$ ions. Thermodynamic investigations have shown that the adsorption phenomenon of $\mathrm{Cr}(\mathrm{vI})$ on PPY-PANI@RHA is endothermic, feasible, and spontaneous in nature. Additionally, the reusability study of the spent PPY-PANI@RHA adsorbent indicated its high removal efficiency for several times. Finally, PPY-PANIaRHA was also successfully used to remove $\mathrm{Cr}(\mathrm{vI})$ ions from the highly polluted raw tannery wastewater sample. Our findings clearly demonstrated that PPY-PANI-coated rice hush ash could be an alternative as an effective bio adsorbent in the removal of $\mathrm{Cr}(\mathrm{vI})$ for wastewater treatment and benefit the industries in the future.
\end{abstract}

\section{Introduction}

The scarcity of safe water is a global threat leading to a severe risk to the environment and human health. This is substantiated by developing sustainable approaches for the successful remediation of pollutants from contaminated water. ${ }^{1-3}$ In this regard, chromium $(\mathrm{Cr})$ is one of the most common heavy metal pollutants usually present in trace amounts in natural waters due to its wide range of application in electroplating, steel production, pigments, alloying, tanning of leather, textile dyes, chemical manufacturing, metal corrosion, inhibitors, refractory bricks, batteries, mordants, and several other industrial

\footnotetext{
${ }^{a}$ School of Water Resources, Indian Institute of Technology Kharagpur, Kharagpur, West Bengal-721302, India

${ }^{b}$ Department of Chemistry, Indian Institute of Technology Kharagpur, Kharagpur, West Bengal-721302, India. E-mail: sunit@chem.iitkgp.ac.in ${ }^{c}$ Environmental Engineering Division, Department of Civil Engineering,

Indian Institute of Technology Kharagpur, Kharagpur, West Bengal-721302, India. E-mail: agupta@civil.iitkgp.ac.in

$\dagger$ Electronic supplementary information (ESI) available. See DOI: 10.1039/ d0ma00862a
}

applications. ${ }^{4-8}$ The discharge of untreated or poorly treated effluents coming from such industries always poses a severe threat to the abiotic and the biotic environment leading to the contamination of natural resources of soil and water. ${ }^{1,9}$ Though $\mathrm{Cr}$ exists in several oxidation states ranging from II to VI, only trivalent chromium (Cr(III)) and hexavalent chromium ( $\mathrm{Cr}(\mathrm{VI})$ ) species remain the most stable and common forms of $\mathrm{Cr}$ in the environment. ${ }^{10} \mathrm{Cr}$ (III) exists in the form of oxides, hydroxides, and sulphates, and is insoluble in water. However, its lower mobility enables it to be mostly bound to the organic matter in soil and aquatic environments. This is also considered a micronutrient for humans and is necessary for sugar and lipid metabolism. In contrast, $\mathrm{Cr}(\mathrm{VI})$ is more toxic than $\mathrm{Cr}(\mathrm{III})$ and shows high solubility in water under circumneutral $\mathrm{pH}$ conditions, and poses a serious risk to human health on exposure. ${ }^{11}$ In humans, it leads to mutations, skin corrosion, lung cancer, irritations in the respiratory tract and eyes, gastric damage, etc. ${ }^{12}$ The World Health Organization (WHO) recommends $0.05 \mathrm{mg} \mathrm{L}^{-1}$ of $\mathrm{Cr}(\mathrm{vI})$ in drinking water as the permissible limit. ${ }^{13}$ According to the US Environmental Protection Agency (EPA), the acceptable limit of $\mathrm{Cr}(\mathrm{vI})$ for industrial effluent discharge into surface water is $0.10 \mathrm{mg} \mathrm{L}^{-1} \cdot{ }^{14}$ 
Among different methodologies, adsorption is considered to be the most acceptable technique for the removal of $\mathrm{Cr}(\mathrm{vI})$ from wastewater. This is mainly due to easy operation, high selectivity, high removal efficiency, and reusability property in the adsorption of $\mathrm{Cr}(\mathrm{vI}){ }^{6,15}$ Therefore, several studies have been performed for the removal of $\mathrm{Cr}(\mathrm{vI})$ using various adsorbents such as silica, activated carbon, clay, metal oxides, bauxite, biomaterials, zeolites, layered double hydroxide, etc. ${ }^{5,16-18}$ Besides, hybrid materials, such as titanium cross-linked chitosan, ${ }^{19}$ magnetic carbon nanoadsorbent, ${ }^{20} \mathrm{C} @ T i O_{2},{ }^{21}$ etc., have also been employed as adsorbents in the separation of pollutants from contaminated water. The choice of hybrid nanocomposites in this and several other works is guided by its high surface/volume ratio, high selectivity, better mechanical properties, high effective surface area, a large number of active sites, and high reactivity. ${ }^{22-24}$

Recently, conducting polymers, in particular polyaniline (PANI) and polypyrrole (PPY), have been receiving considerable attention due to their multifaceted applications, such as electrochemical display devices, molecular electronics, non-linear optics, sensors, electromagnetic shielding batteries, water treatment, supercapacitors, wave-absorbing fields, etc. ${ }^{25-29}$ Besides, PANI and PPY have also been used as adsorbents in the remediation of $\mathrm{Cr}(\mathrm{vI})$ from aqueous media. ${ }^{30-34}$ The choice of PANI and PPY in this work was mainly guided by their easy bulk synthesis, biocompatibility, redox properties, large specific surface area, non-toxicity, and low cost. ${ }^{32,35-39}$ Furthermore, the presence of a nitrogen atom with a lone pair of electrons in PPY and PANI through its efficient binding (electrostatic/ hydrogen) in the macromolecular chains facilitates the removal of $\mathrm{Cr}(\mathrm{vI})$ ions from contaminated water. ${ }^{40-42}$ In this context, limited work has been reported on the removal of $\mathrm{Cr}(\mathrm{vI})$ using the PANI-PPY copolymer as an adsorbent. ${ }^{10,43}$ However, after treatment, eluting the PANI and PPY powder is a very tedious and expensive task due to its intrinsic hydrophilicity. ${ }^{39}$ Furthermore, the processability of PANI and PPY remains another grey area for their potential commercial applications. ${ }^{44}$ Therefore, different approaches have been directed to conducting polymers, such as grafting of polyaniline to a non-conducting poly-( $p$-phenylene terephthalamide) polymer, ${ }^{45}$ pyrrole-styrene graft copolymer, ${ }^{46}$ etc. In addition, reports are also available on the adsorption of $\mathrm{Cr}(\mathrm{vI})$ ions from contaminated water using polypyrrole/calcium rectorite composites, ${ }^{6}$ core-shell $\mathrm{Fe}_{3} \mathrm{O}_{4} / \mathrm{PANI}$ microspheres, ${ }^{34} \mathrm{PPy} / \mathrm{Fe}_{3} \mathrm{O}_{4}$ magnetic nanocomposites, ${ }^{38}$ capsular polypyrrole hollow nanofibers, ${ }^{30}$ chitosan/polypyrrole, ${ }^{47}$ polyaniline@Ni(OH $)_{2},{ }^{48}$ flake-like polyaniline/montmorillonite nanocomposites, ${ }^{49} \mathrm{Fe}_{3} \mathrm{O}_{4} @ A r g-P P y,{ }^{50}$ sodium alginate-polyaniline nanofibers ${ }^{51}$ bacteria cell templated porous polyaniline, ${ }^{42}$ alkyl-substituted polyaniline/chitosan, ${ }^{52}$ polypyrrole-modified layered double hydroxides, ${ }^{53}$ graphene/ $\mathrm{SiO}_{2} @$ @polypyrrole, ${ }^{54}$ and PANI-coated electrospun adsorbent membranes. ${ }^{55}$

In recent years, attention has been paid to harnessing a wide variety of low-cost natural materials and evaluating their efficiency and adsorption capacity in removing harmful contaminants from water. ${ }^{56}$ In this regard, much effort has been devoted to fabricating various PPY and PANI coatings on low-cost, ecofriendly promising bio-adsorbents, such as sawdust, sugarcane bagasse, rice husks, rice husk ash, chitin, coconut coir and used them as an adsorbent for the removal of heavy metals from wastewater. ${ }^{41,44,57-59}$ Among these, owing to its production in Asia in enormous quantities, sustainable, and low-cost rice husk has been receiving considerable attention as an effective adsorbent for the removal of various pollutants from water and wastewaters. ${ }^{60}$ Studies have also been conducted on utilizing rice husk in the preparation of rice husk ash (RHA) comprising $\mathrm{SiO}_{2}$ ( $\left.\sim 94.50 \%\right), \mathrm{CaO}(\sim 1.80 \%), \mathrm{Al}_{2} \mathrm{O}_{3}(\sim 0.29 \%)$, and other minor mineral element composition and using it as an adsorbent in the removal of pollutants present in contaminated water. $^{41,60-62}$ The inclusion of silica in a variety of conjugated polymers is reported to alter their physical properties. For example, according to Dutta and De, ${ }^{63}$ the effective surface area increases with the $\mathrm{SiO}_{2}$ concentration, and the conjugation length of PANI is reduced after the incorporation of silica. This aspect is found to be very useful in the processability and recycling of PANI incorporated silica in making it an effective adsorbent in the removal of $\mathrm{Cr}(\mathrm{vI})$ from aqueous solutions. ${ }^{64}$ However, no efforts were made on the synthesis of the PPY-PANI copolymer coated on RHA as an easily processable adsorbent in the removal of $\mathrm{Cr}(\mathrm{vI})$ from aqueous media. It is anticipated that an increase in the surface area of the PPY-PANI composite could enhance the uptake of pollutants compared to the PPY and PANI alone through adsorption. Alternatively, PPY-PANI polymers could also overcome the restraint of the rareness of new conjugated $\pi$-bondcontaining monomers. ${ }^{65,66}$

In view of this, the present work is focused on the synthesis of PPY-PANI composite coated rice husk ash (RHA) and explore its utility as a potential adsorbent in the removal of $\mathrm{Cr}(\mathrm{vI})$ from contaminated water. The preparative method involved in situ deposition of the PPY-PANI composite coated by in situ chemical oxidative polymerization on rice husk ash (referred to as PPY-PANI@RHA) and characterization. Subsequently, investigations have been conducted to evaluate its ability as an adsorbent for selective removal of $\mathrm{Cr}(\mathrm{vI})$ from contaminated aqueous solutions, including real wastewater. Our studies have shown significantly enhanced maximum adsorption capacity (769.15 $\mathrm{mg} \mathrm{g}^{-1}$ ) of $\mathrm{Cr}(\mathrm{vI})$ compared to that of several other adsorbents. The effect of various parameters including $\mathrm{pH}$, dose, time, initial concentration, and co-existing ions on $\mathrm{Cr}(\mathrm{vI})$ adsorption efficiency has also been investigated in this study. Furthermore, the adsorption kinetics, adsorption isotherms, and thermodynamics of the adsorption process have also been studied. Finally, an adsorption study on the removal of $\mathrm{Cr}(\mathrm{vI})$ from industrial contaminated effluents has also shown promising outcomes.

\section{Experimental section}

\subsection{Materials and reagents}

Details about the materials and reagents are provided in the ESI. $\dagger$ 


\subsection{Material synthesis}

Synthesis of rice husk ash (RHA). The rice husks, a byproduct obtained from the local rice mill, was washed several times with distilled water and kept for drying in a hot air oven at $\sim 333 \mathrm{~K}$ for 12 hours. Subsequently, rice husk was subjected to pre-treatment with $1 \mathrm{M} \mathrm{HCl}$ prior to its combustion to produce pure white silica powder. ${ }^{61}$ Subsequently, it was subjected to washing with DI water several times to remove the extra acid and thereafter, placed in an oven at $333 \mathrm{~K}$ for 24 hours. This was followed by heating the resultant product in a muffle furnace at $973 \mathrm{~K}$ for 4 hours to form white rice husk ash powder. ${ }^{41}$

Synthesis of polypyrrole-polyaniline@rice husk ash (PPY-PANI@RHA). First, $0.1 \mathrm{~g}$ of RHA was dispersed in $10 \mathrm{ml}$ of DI water in a beaker. In another experiment, $0.3 \mathrm{ml}$ of pyrrole and $0.15 \mathrm{ml}$ of aniline monomers were individually mixed with $10 \mathrm{ml}$ of DI water in separate beakers and doped with $1 \mathrm{M} \mathrm{HCl}$ and simultaneously added to the dispersion of RHA with stirring at room temperature for 5-6 hours. After that, $0.15 \mathrm{~g}$ of APS dissolved in DI water was added to the previous solution and kept in an ice bath for 12 hours. The product (referred to as PPY-PANI@RHA) formed in this manner was washed rapidly with DI water several times and finally kept in a vacuum oven at $333 \mathrm{~K}$ for 24 hours. The detailed synthesis process of PPYPANI@RHA has been schematically described in Fig. 1.

\subsection{Adsorption experiments}

The adsorption experiments were conducted in polyethylene bottles (Tarson Co. Ltd, India) with a capacity of $250 \mathrm{ml}$ containing $100 \mathrm{ml}$ of aqueous $\mathrm{Cr}(\mathrm{vI})$ solutions of different concentrations and $0.8 \mathrm{~g} \mathrm{~L}^{-1}$ of PPY-PANI@RHA (adsorbent dosage) unless otherwise mentioned. The solution $\mathrm{pH}$ was maintained at $\sim 2$ using $0.1 \mathrm{M} \mathrm{HCl}$, and then the sample bottles were placed in a thermostatic shaker for agitation at $200 \pm 10 \mathrm{rpm}$ in the time range of 2 to $700 \mathrm{~min}$. Subsequently, the adsorbent was separated by filtering the respective solution using $0.22 \mu \mathrm{m}$ Whatman Nylon filter membranes. Thereafter, the $\operatorname{Cr}(\mathrm{vI})$ content in the supernatant liquid was evaluated by using a UV-visible spectrophotometer. The maximum intensity of absorbance $(540 \mathrm{~nm})$ was measured corresponding to the formation of the intense red-violet chromophore complex due to the reaction between $\mathrm{Cr}(\mathrm{vI})$ and 1,5-diphenyl carbazide in acidic medium. ${ }^{6,67}$ Accordingly, the \% removal of $\mathrm{Cr}(\mathrm{vI})$ was calculated as follows:

$$
\% \text { Removal }=\frac{\left(C_{0}-C_{t}\right)}{C_{0}} \times 100
$$

where $C_{0}$ and $C_{t}$ indicate the initial concentration of $\mathrm{Cr}(\mathrm{vI})$ and the concentration at any given time $(t)$, respectively. The $q_{t}$ represents the adsorption capacity at any time ' $t$ ' and the following equation is used to calculate the value:

$$
q_{t}=\frac{\left(C_{0}-C_{t}\right) V}{m}
$$

where the mass of the adsorbent is denoted by $m(\mathrm{~g})$, and $V(\mathrm{~L})$ is the volume of the $\mathrm{Cr}(\mathrm{vI})$ solution. The reproducibility of the batch study results was checked by triplicating every adsorption experiment and was found to be within the acceptable limits. The effects of $\mathrm{pH}$, contact time, adsorbent dose, and temperature on $\mathrm{Cr}(\mathrm{vI})$ adsorption capacity were also explored. In addition, the adsorption isotherms and thermodynamic data were generated by performing the experiments at three different temperatures (293 K, $303 \mathrm{~K}$, and $313 \mathrm{~K})$.

\subsection{Desorption and reusability experiments}

The adsorption-desorption tests were implemented to study the regeneration and reusability of the spent adsorbent for the removal of $\mathrm{Cr}(\mathrm{vI})$. Accordingly, $0.8 \mathrm{~g} \mathrm{~L}^{-1}$ dose of PPY-PANI@ RHA was added to $100 \mathrm{ml}$ of $100 \mathrm{mg} \mathrm{L}^{-1}$ of $\mathrm{Cr}(\mathrm{vI})$ solutions and subjected to agitation for 4 hours at $200 \mathrm{rpm}$ followed by collection of the spent adsorbent by filtering the solutions. In desorption experiments, Cr(vI)-loaded PPY-PANI@RHA were treated with $\mathrm{NaOH}(0.1$ to $1 \mathrm{M})$ solution for 4 hours at $200 \mathrm{rpm}$,

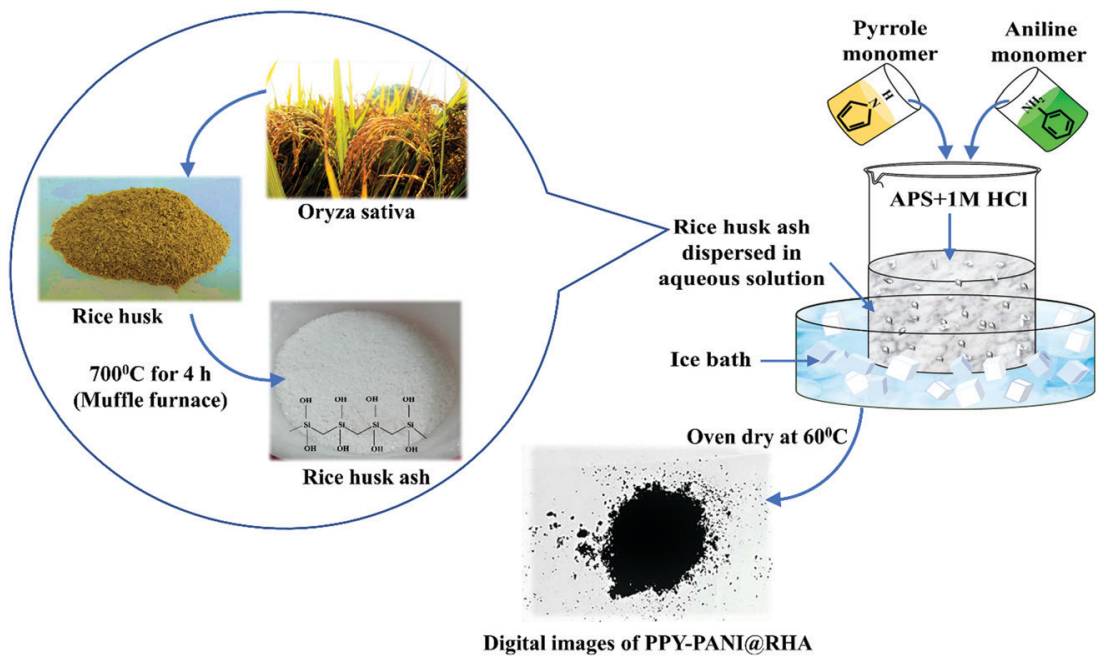

Fig. 1 Schematic representation of the synthesis process of polyprrole-polyaniline coated rice husk ash. 
then filtered, and the concentration of $\mathrm{Cr}(\mathrm{vI})$ in the residual solution was evaluated. After that, the surface of the spent adsorbent was activated and regenerated by treating it with $2 \mathrm{M}$ $\mathrm{HCl}$ for 2 hours, followed by collection and drying of the sample for reuse. ${ }^{6,38}$ Subsequently, five successive desorption-adsorption cycles were performed to confirm the reusability properties of PPY-PANI@RHA for the adsorption of $\mathrm{Cr}(\mathrm{vI})$ from aqueous solutions.

\subsection{Characterization technique}

The details about the various techniques used in the characterization of the material are provided in the ESI. $\dagger$

\section{Results and discussion}

\subsection{Characterization of PPY-PANI@RHA}

Morphological analysis. The surface morphology of PPYPANI, RHA, and PPY-PANI@RHA composites was studied by FE-SEM, and the corresponding images are displayed in Fig. 2(a), (b), and (c), respectively. It is noted that PPY-PANI showed the formation of a relatively uniform spherical morphology without using any template. However, the surface morphology of rice husk ash appeared to be porous due to the burning out of the organic component of $\mathrm{RH}$ and the formation of silica. ${ }^{68}$ The image of PPY-PANI@RHA showed a homogeneous deposition of PPY-PANI on the surface of RHA. The FE-SEM images of PPY-PANI@RHA following Cr(vi) adsorption is also displayed in Fig. 2(d). The presence of a relatively smooth
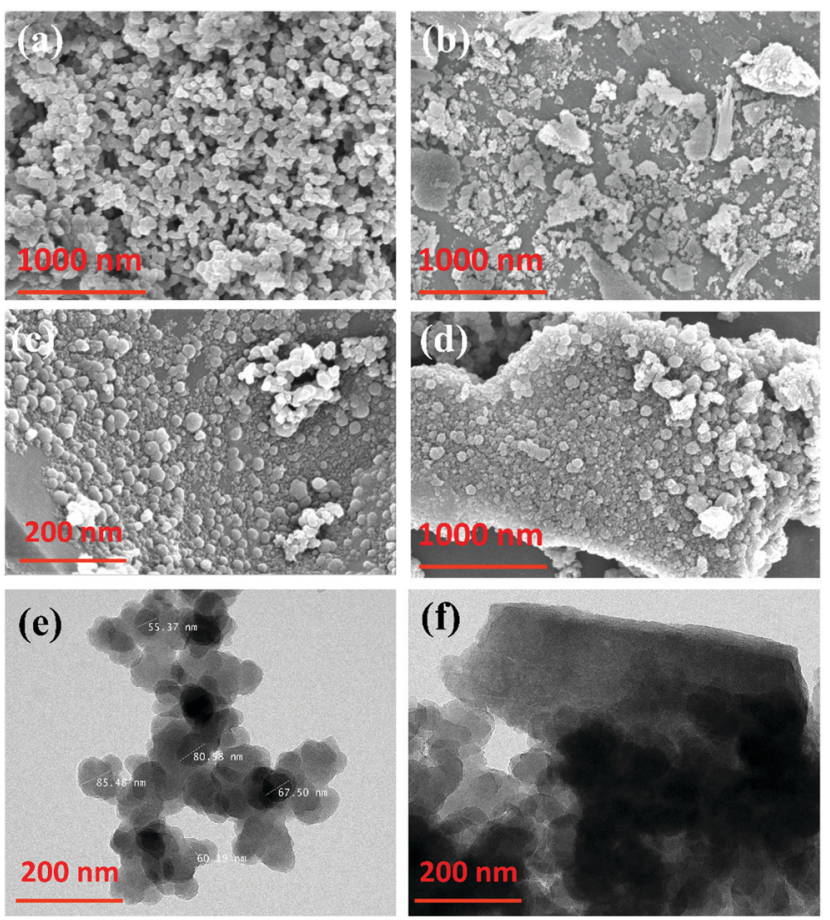

Fig. 2 FE-SEM images of (a) PPY-PANI, (b) RHA, (c) PPY-PANI@RHA before $\mathrm{Cr}(\mathrm{vl})$ adsorption, and (d) PPY-PANIaRHA after adsorption of $\mathrm{Cr}(\mathrm{vI})$, and HR-TEM images of (e) PPY-PANI and (f) PPY-PANIaRHA nanocomposites. surface morphology is clearly apparent from the adsorption of Cr(vi) on the surface of PPY-PANI@RHA, including surface agglomeration of PPY-PANI. ${ }^{52,69}$

HR-TEM analysis was also performed to gain a clear understanding of the prepared PPY-PANI and PPY-PANI@RHA composites, and the corresponding findings are displayed in Fig. 2(e) and (f), respectively. It visibly demonstrated a uniform size spherical morphology of PPY-PANI polymer matrixes by forming an interconnected network. HR-TEM studies further reaffirmed our contention based on FE-SEM on the formation of uniformly deposited PPY-PANI on the surface of RHA and successful formation of the PPY-PANI@RHA composite. The composition of PPY-PANI@RHA has also been studied by thin film standardless quantitative analysis inferred from TEM analysis and the corresponding findings are displayed in Fig. S1 (ESI $\dagger$ ). The presence of the $\mathrm{C}, \mathrm{N}, \mathrm{O}$, and $\mathrm{Si}$ peaks indicate the co-existence of polypyrrole, polyaniline, and rice husk ash in the composite material (PPY-PANI@RHA).

XRD analysis. The XRD patterns of PPY, PANI, RHA, PPYPANI@RHA, and Cr(vi) adsorbed PPY-PANI@RHA nanocomposites are displayed in Fig. 3(a). A broad peak in the XRD pattern of PPY at $2 \theta \sim 24^{\circ}$ indicates its amorphous nature attributed to the repetition of the pyrrole units. ${ }^{53}$ The XRD pattern of PANI shows the presence of a broad peak centered around $2 \theta \sim 25^{\circ}$ due to the periodicity perpendicular and parallel to the polymer chain owing to the formation of partly crystalline PANI. ${ }^{39,70}$ The appearance of a signature peak at $2 \theta \sim 23^{\circ}$ in the XRD pattern of RHA corresponds to the amorphous silica. ${ }^{71}$ The presence of a broad peak at around $2 \theta \sim 24^{\circ}$ in PPY-PANI@RHA composites could be ascribed to the co-existence of PPY, PANI, and RHA. Furthermore, the intensity of the diffraction peak in PPY-PANI@RHA is considerably decreased due to the surface coating of RHA with PPY-PANI nanocomposites. ${ }^{6}$ It is also evident from the XRD patterns that PPY-PANI@RHA after adsorption of Cr(vi) showed no significant characteristic changes compared to the pure PPY-PANI@RHA adsorbent. $^{50}$

FTIR analysis. The chemical structures of the RHA and PPYPANI@RHA before/after $\mathrm{Cr}(\mathrm{vI})$ adsorption were investigated by FTIR analysis in the wavenumber range of $400-4000 \mathrm{~cm}^{-1}$, and the corresponding findings are displayed in Fig. 3(b). The appearance of bands around 1075 (asymmetric stretching) and $797 \mathrm{~cm}^{-1}$ (symmetric stretching) in the spectra of RHA corresponds to $\mathrm{Si}-\mathrm{O}-\mathrm{Si}$ due to the presence of silica. ${ }^{61,72}$ The characteristic peaks of pyrrole in the spectra of PPYPANI@RHA appeared at 1552, 1490, 1300, 1110, 1048, 925 and $800 \mathrm{~cm}^{-1}$, corresponding to the angular deformation of the $\mathrm{N}-\mathrm{H}$ group of primary amines present in polypyrrole, conjugated $\mathrm{C}-\mathrm{N}$ stretching, $\mathrm{C}-\mathrm{N}$ stretching vibration, $\mathrm{C}-\mathrm{H}$ stretching vibration, $\mathrm{N}-\mathrm{H}$ in-plane deformation, and $\mathrm{C}-\mathrm{H}$ deformation, respectively. ${ }^{44,57,73}$ Furthermore, the presence of the peaks at $1590 \mathrm{~cm}^{-1}\left(\mathrm{C}=\mathrm{N}\right.$ stretching), $1552 \mathrm{~cm}^{-1}(\mathrm{C}-\mathrm{N}$ stretching), and $1300 \mathrm{~cm}^{-1}\left(\mathrm{~N}-\mathrm{H}\right.$ deformation), ${ }^{74}$ along with $1490 \mathrm{~cm}^{-1}$ (C-C bonding of benzenoid structure), $1105 \mathrm{~cm}^{-1}$ (vibration in the $-\mathrm{NH}^{+}=$structure) and $795 \mathrm{~cm}^{-1}$ (C-Cl out-ofplane bending vibration) could be attributed to the presence of 

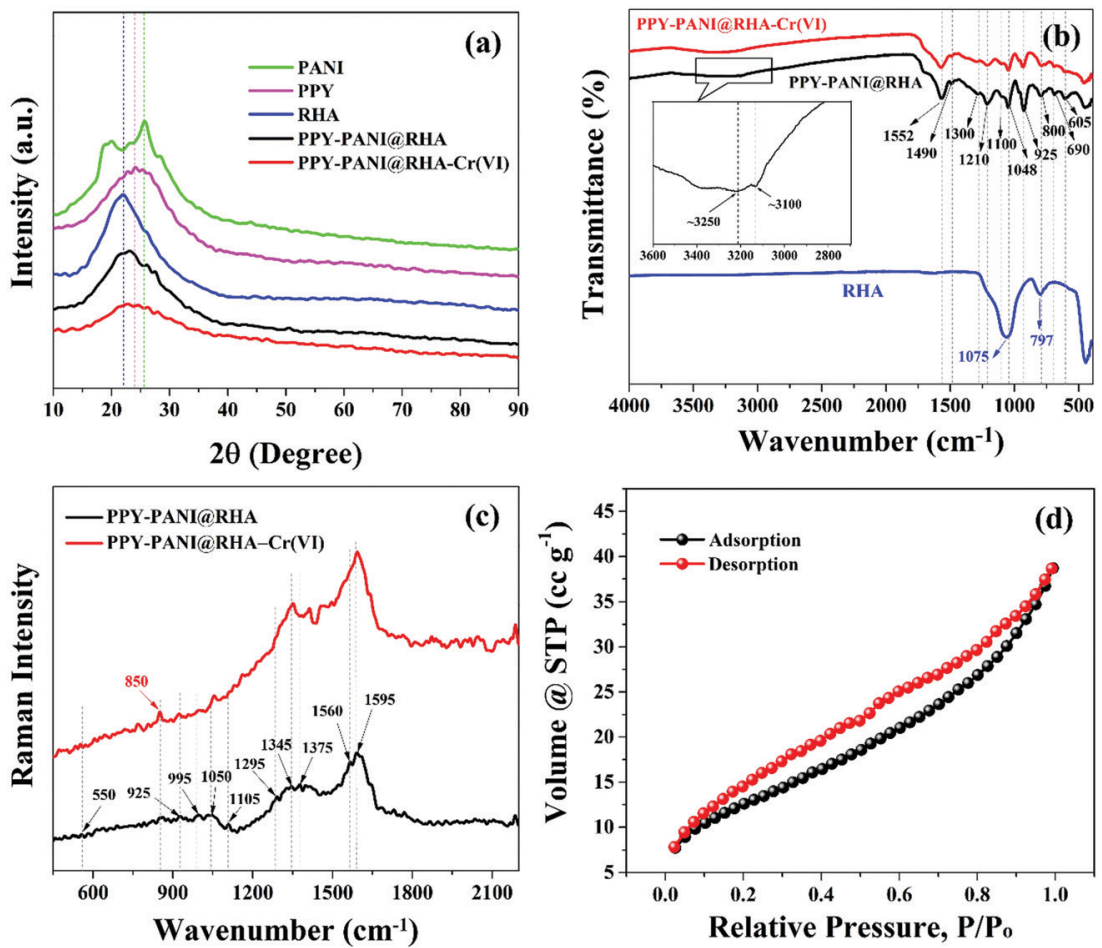

Fig. 3 (a) XRD pattern of PPY-PANI@RHA, PANI, PPY, RHA and PPY-PANI@RHA-Cr(vI) adsorbed composites, (b) FTIR spectra of RHA and PPY-PANICRHA composites before and after Cr(vi) adsorption, (c) Raman spectra of the PPY-PANICRHA composite before and after adsorption of $\mathrm{Cr}(\mathrm{VI})$, (d) $\mathrm{N}_{2}$ adsorption-desorption isotherm measured for PPY-PANI@RHA.

doped polyaniline in PPY-PANI@RHA. ${ }^{75,76}$ The FTIR spectra of PPY-PANI@RHA also indicate the presence of a broad peak at $\sim 3250 \mathrm{~cm}^{-1}$ corresponding to the symmetric and unsymmetrical $\mathrm{N}-\mathrm{H}$ stretching. ${ }^{22}$ The absorption band in the range of $\sim 3100 \mathrm{~cm}^{-1}$ is characteristic of stretching vibrations of $=\mathrm{C}-\mathrm{H}^{23}$ The presence of overlapped absorption bands of PPY, PANI, and RHA is a clear indication of PPY-PANI deposited on the surface of silica in rice husk ash. ${ }^{10,77}$ The change in the intensity and shape of the peaks in PPY-PANI@RHA and Cr(vi) adsorbed PPY-PANI@RHA confirmed the presence of interactions between PPY, PANI, RHA, and $\mathrm{Cr}(\mathrm{v})$ ions with the porous surface of PPY, PANI, and RHA, respectively. ${ }^{44}$

Raman spectroscopy analysis. Raman spectroscopy analysis has been conducted before and after $\mathrm{Cr}(\mathrm{vI})$ adsorption on PPY-PANI@RHA, and the corresponding findings are displayed in Fig. 3(c). The spectra showed the presence of characteristic peaks of PPY located at $1595 \mathrm{~cm}^{-1}$ and $1560 \mathrm{~cm}^{-1}$ due to the stretching vibrations of the $\mathrm{C}=\mathrm{C}$ and $\mathrm{C}-\mathrm{C}$ bonds along with the entire chain, respectively. ${ }^{53,78,79}$ In addition, another band located at $925 \mathrm{~cm}^{-1}$ along with a doublet at 1345 and $1375 \mathrm{~cm}^{-1}$ appeared due to the ring deformation associated with bipolaron and ring-stretching modes of polypyrrole, respectively. ${ }^{78-80}$ Furthermore, a transition is observed from reduced to oxidized polypyrrole in the range of $1560 \mathrm{~cm}^{-1}$ to $1620 \mathrm{~cm}^{-1} \cdot{ }^{81}$ Fig. 3(c) also shows the presence of peaks at around $550 \mathrm{~cm}^{-1}$ due to the bending vibrations of $\mathrm{Si}-\mathrm{O}_{\mathrm{b}}-\mathrm{Si}$ bonds (oxygen bridging two silicate tetrahedra). In addition, another peak is also observed at $1050 \mathrm{~cm}^{-1}$, corresponding to the stretching vibrations of $\mathrm{Si}-\mathrm{O}_{\mathrm{nb}}$ bonds (non-bridging oxygen bonded to $\mathrm{Si}) .{ }^{82}$ All these findings clearly demonstrate the incorporation of PPY-PANI and RHA in the synthesized composite material. The Raman spectra of $\mathrm{Cr}(\mathrm{vI})$ adsorbed PPYPANI@RHA show the appearance of a peak at $\sim 849.7 \mathrm{~cm}^{-1}$ due to the interaction between chromate ions and PPY-PANI composites. $^{18,83}$

BET analysis. The BET surface area of PPY-PANI@RHA was measured using the $\mathrm{N}_{2}$ adsorption-desorption technique in the presence of liquid nitrogen and was found to be $\sim 23.52 \mathrm{~m}^{2} \mathrm{~g}^{-1}$, and based on this, the corresponding plot is displayed in Fig. 3(d). It is observed that the BET surface area of the PPY-PANI@RHA nanocomposite is higher than many other reported PPY/PANI/ RHA materials. $^{35,36,47,50,84}$ The Barrett-Joyner-Halenda (BJH) pore size distribution plot of PPY-PANI@RHA is displayed in Fig. S2 $(\mathrm{ESI} \dagger)$. Based on this, the average pore diameter and cumulative pore volume of PPY-PANI@RHA were found to be $44.16 \AA$ and $0.04 \mathrm{~cm}^{3} \mathrm{~g}^{-1}$, respectively.

\subsection{Batch study on $\mathrm{Cr}(\mathrm{vI})$ removal from aqueous solution using PPY-PANI@RHA}

Effect of initial concentration of the adsorbate on the adsorption of $\mathbf{C r}(\mathrm{vI})$. The percentage removal of $\mathrm{Cr}(\mathrm{vI})$ has been studied as a function of the initial $\mathrm{Cr}(\mathrm{vI})$ concentration (10 to $\left.1000 \mathrm{mg} \mathrm{L}^{-1}\right)$ at a fixed PPY-PANI@RHA dose $\left(0.8 \mathrm{~g} \mathrm{~L}^{-1}\right)$ and $\mathrm{pH} \sim 2$ at three different temperatures $(293 \mathrm{~K}, 303 \mathrm{~K}$ and, $313 \mathrm{~K}$ ), and the corresponding findings are represented in Fig. 4(a). This is inferred that \% removal of $\mathrm{Cr}(\mathrm{vI})$ decreased 

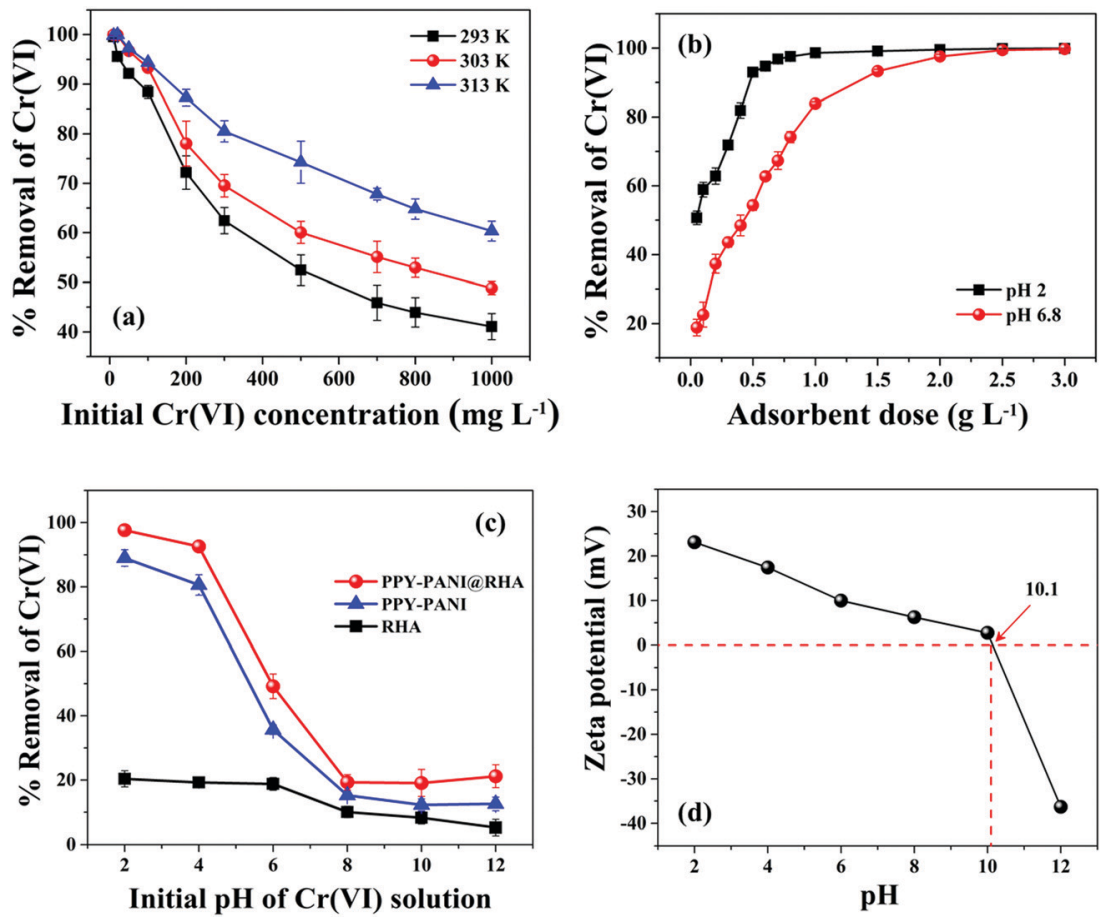

Fig. 4 Effect of (a) initial concentration of $\mathrm{Cr}(\mathrm{vI})$ at a different temperature (PPY-PANICRHA dose: $0.8 \mathrm{~g} \mathrm{~L}^{-1}$; contact time: 300 min; agitation speed: 200 rpm; pH 2), (b) adsorbent dose at pH 2 and without $\mathrm{pH}$ ( 6.8) adjustment (initial $\mathrm{Cr}(\mathrm{vI})$ concentration: 50 mg L ${ }^{-1}$; contact time: 300 min; agitation speed: 200 rpm; temperature: 303 K), (c) initial solution pH on \% removal of $\mathrm{Cr}(\mathrm{VI})$ by PPY-PANI(aRHA, PPY-PANI and RHA adsorbents (Initial Cr(VI) concentration: $50 \mathrm{mg} \mathrm{L}^{-1}$; contact time: $300 \mathrm{~min}$; agitation speed: $200 \mathrm{rpm}$; temperature: $303 \mathrm{~K}$ ), and (d) variation of zeta potential of PPY-PANI@RHA at different $\mathrm{pH}$.

with the increase in the adsorbate concentration in the presence of PPY-PANI@RHA at all three temperatures, and this is possibly due to the saturation of sorption sites. ${ }^{47}$ The $\%$ removal of $\mathrm{Cr}(\mathrm{vI})$ reduced from 99.59 to $41.06 \%, 99.95$ to $48.83 \%$, and 99.86 to $60.34 \%$ corresponding to the initial $\mathrm{Cr}(\mathrm{vI})$ concentration of 10 to $1000 \mathrm{mg} \mathrm{L}^{-1}$ at temperatures of $293 \mathrm{~K}, 303 \mathrm{~K}$, and $313 \mathrm{~K}$, respectively. The corresponding findings also indicate the increase of \% removal of $\mathrm{Cr}(\mathrm{vI})$ by the increase of temperature, which suggested the endothermic nature of the $\mathrm{Cr}(\mathrm{vI})$ adsorption using PPY-PANI@RHA. ${ }^{10,85}$ Based on this, the maximum removal of $\mathrm{Cr}(\mathrm{vI})$ at all initial concentrations could be linked to the increase in the thermal energy of the adsorbing chromium species with the increase of temperature. $^{85}$

Effect of adsorbent dose on the adsorption of $\mathrm{Cr}(\mathrm{vI})$. The effect of adsorbent dose ( 0.05 to $\left.3 \mathrm{~g} \mathrm{~L}^{-1}\right)$ on the removal efficiency of $\mathrm{Cr}(\mathrm{vI})$ has been investigated with its $\mathrm{pH}$ equal to 2 and without adjusting the $\mathrm{pH}(\mathrm{pH} \sim 6.8)$ of the contaminated water for a fixed initial $\mathrm{Cr}(\mathrm{vI})$ concentration $\left(50 \mathrm{mg} \mathrm{\textrm {L } ^ { - 1 } )}\right.$ as displayed in Fig. 4(b). It is noted that the removal efficiency of $\mathrm{Cr}(\mathrm{vI})$ is increased gradually with an adsorbent dose up to $0.8 \mathrm{~g} \mathrm{~L}^{-1}$ (at $\mathrm{pH}=2$ ) and achieved $\sim 98 \%$ of $\mathrm{Cr}(\mathrm{vI})$ removal efficiency. This could be ascribed to the increased adsorbent surface area and the availability of more active adsorption sites. ${ }^{10,38}$ Thereafter, \% removal $\mathrm{Cr}(\mathrm{vI})$ remains more or less unaltered even after increasing the doses (onward $0.8 \mathrm{~g} \mathrm{~L}^{-1}$ ), indicating the attainment of equilibrium. Therefore, further experimental studies have been conducted at an optimum $0.8 \mathrm{~g} \mathrm{~L}^{-1}$ of
PPY-PANI@RHA dose. It is also noted that aqueous solutions with no $\mathrm{pH}$ adjustment $(\mathrm{pH} \sim 6.8)$ followed a similar trend. However, it showed inferior $\mathrm{Cr}(\mathrm{vI})$ removal efficiency up to adsorbent of $1.0 \mathrm{~g} \mathrm{~L}^{-1}$ dose. Fig. 4(b) also shows that maximum $\mathrm{Cr}(\mathrm{vI})$ removal $(\sim 98 \%)$ is recorded at $\mathrm{pH} \sim 2$ solution at a much smaller adsorbent dose $\left(0.8 \mathrm{~g} \mathrm{~L}^{-1}\right)$ compared to that achieved in an aqueous solution without prior $\mathrm{pH}$ adjustment at a higher adsorbent dose $\left(2.5 \mathrm{~g} \mathrm{~L}^{-1}\right)$. Additionally, Fig. S3 (ESI $\dagger$ ) also describes the comparison of $\mathrm{Cr}(\mathrm{vI})$ removal efficiency of PPY-PANI@RHA, RHA, and PPY-PANI by varying the doses $\left(0.5\right.$ to $\left.10 \mathrm{~g} \mathrm{~L}^{-1}\right)$ at a fixed $\mathrm{Cr}(\mathrm{VI})$ initial concentration $\left(50 \mathrm{mg} \mathrm{L}^{-1}\right)$ and $\mathrm{pH} \sim 2$. The result shows the separation of $\mathrm{Cr}(\mathrm{vI})$ to be considerably lower in the presence of RHA and PPY-PANI adsorbents over the entire range of doses compared to PPY-PANI@RHA composites. The enhanced chromium removal percentages of composite material (PPY-PANI@RHA) are probably due to the synergic effect between RHA and polypyrrole-polyaniline nanocomposites. ${ }^{31,48,86}$

\section{Effect of solution $\mathrm{pH}$ on the adsorption of $\mathrm{Cr}(\mathrm{vI})$}

The $\mathrm{pH}$ of the solution plays a very significant role in the adsorption of chromium species due to its control on the surface charges of the adsorbent. ${ }^{38}$ Fig. 4 (c) refers to the room temperature variation of $\% \mathrm{Cr}(\mathrm{vI})$ removal as a function of initial $\mathrm{pH}$ of the solution corresponding to a fixed amount $\left(0.8 \mathrm{~g} \mathrm{~L}^{-1}\right)$ of RHA, PPY-PANI, and PPY-PANI@RHA. It is clearly evident that the adsorption characteristic of the $\mathrm{Cr}(\mathrm{VI})$ is highly dependent on $\mathrm{pH}$ as well as the nature of the adsorbents. 
Fig. 4(c) shows that the separation of $\mathrm{Cr}(\mathrm{vI})$ is considerably lower in the presence of RHA and PPY-PANI adsorbents over the entire range of $\mathrm{pH}$. In contrast, the removal efficiency $\mathrm{Cr}(\mathrm{vI})$ in the presence of PPY-PANI@RHA decreased sharply from $97.64 \%$ to $21.18 \%$, corresponding to $\mathrm{pH}$ values of 2 to 12 , respectively. Therefore, all other adsorption experiments were conducted at $\mathrm{pH} 2$ to ensure the maximum removal of $\mathrm{Cr}(\mathrm{vI})$ by the PPY-PANI@RHA. It may be noted that $\mathrm{Cr}(\mathrm{vI})$ exists in several stable forms such as $\mathrm{CrO}_{4}{ }^{2-}, \mathrm{HCrO}_{4}{ }^{-}$, and $\mathrm{Cr}_{2} \mathrm{O}_{7}{ }^{2-}$ in aqueous solutions depending on the $\mathrm{pH}$ of the solution and chromium concentration. ${ }^{87}$ When $\mathrm{pH}$ is in the range of 1 to 5 , $\mathrm{HCrO}_{4}{ }^{-}$is reportedly one of the most dominant species with only a small amount of $\mathrm{Cr}_{2} \mathrm{O}_{7}{ }^{2-}$ and $\mathrm{H}_{2} \mathrm{CrO}_{4}$ in $\mathrm{Cr}(\mathrm{vI}) .{ }^{6}$ In contrast, $\mathrm{HCrO}_{4}{ }^{-}$is rapidly converted to $\mathrm{CrO}_{4}{ }^{2-}$ with an increase in the $\mathrm{pH}$ value. Our findings showed a maximum $\mathrm{Cr}(\mathrm{vI})$ removal rate of $97.64 \%$ from the aqueous solution at an optimum $\mathrm{pH}$ value of 2 . It is anticipated that PPY chains are highly protonated for the solution, with its $\mathrm{pH}$ in the range of 1-5. This accounts for the ion-exchange between doped $\mathrm{Cl}^{-}$ions on the adsorbent surface with the $\mathrm{HCrO}_{4}{ }^{-}$ions in the $\mathrm{Cr}(\mathrm{vI})$ solution. ${ }^{6,10,85}$

In order to strengthen this above statement, the point of zero charge (PZC) on the surface of PPY-PANI@RHA was estimated by studying the $\mathrm{pH}$ variation with zeta $(\zeta)$ potential, as displayed in Fig. 4(d). The PZC of PPY-PANI@RHA corresponding to the $\mathrm{pH}$ value of $10.1\left(\mathrm{pH}_{\mathrm{PZC}}\right)$, below and above this value, indicates the adsorbent surface to be positively and negatively charged, respectively. ${ }^{50,87}$ This reforms our earlier contention that the surface of the PPY-PANI@RHA at pH $<$ $\mathrm{pH}_{\mathrm{PZC}}$ is highly protonated with positive charge amine functional groups $\left(-\mathrm{NH}-,-\mathrm{N}<,-\mathrm{NH}_{2}\right)$ and facilitates the electrostatic attraction of $\mathrm{HCrO}_{4}{ }^{-}$species and accounts for its effective removal from aqueous solutions. ${ }^{40,50}$ Our findings also showed that surface protonation becomes insignificant with increasing $\mathrm{pH}$ in alkaline environments. This could be ascribed to the negatively charged ions $\left(\mathrm{OH}^{-}\right)$developed on the adsorbent surface. ${ }^{59}$ As a result, the significantly low adsorption efficiency of the PPY-PANI@RHA is observed due to the electrostatic repulsion between the adsorbent surface and negatively charged $\mathrm{Cr}(\mathrm{vI})$ species. ${ }^{48}$ In addition, as the $\mathrm{pH}$ of the solution is increased $\left(\mathrm{pH}>\mathrm{pH}_{\mathrm{PZC}}\right.$ ), excess $\mathrm{OH}^{-}$ions present in the solution could also compete with negatively charged $\mathrm{Cr}(\mathrm{vI})$ species (i.e., $\mathrm{CrO}_{4}{ }^{2-}$ ) for the adsorption sites in PPY-PANI@RHA and results in the poor removal of $\mathrm{Cr}(\mathrm{vI}) .{ }^{6,47}$ Thus, it is clearly seen that the initial solution $\mathrm{pH}$ has a significant impact on the adsorption of $\mathrm{Cr}(\mathrm{vI})$ from contaminated water.

Effect of contact time on the adsorption of $\mathbf{C r}(\mathrm{vI})$. The effect of contact time varying from 2 to $720 \mathrm{~min}$ on the \% removal of $\mathrm{Cr}(\mathrm{vI})$ was studied at three different initial $\mathrm{Cr}(\mathrm{vI})$ concentrations (50, 75, and $\left.100 \mathrm{mg} \mathrm{L}^{-1}\right)$ at a fixed dose of PPY-PANI@RHA $\left(0.8 \mathrm{~g} \mathrm{~L}^{-1}\right)$, and the corresponding findings are displayed in Fig. 5(a). It is noted that initially, \% removal of $\mathrm{Cr}(\mathrm{vI})$ is increasing rapidly with an increase in the contact time for all three initial concentrations of $\mathrm{Cr}(\mathrm{vI})$. Also, the result shows that within $2 \mathrm{~min}$, the removal efficiency has reached almost 57\%, $51 \%$, and $51 \%$ for the initial $\mathrm{Cr}(\mathrm{VI})$ concentrations of 50,75 , and $100 \mathrm{mg} \mathrm{L}^{-1}$, respectively. Initially, such rapid adsorption of
$\mathrm{Cr}(\mathrm{vI})$ species could be attributed to the availability of a high concentration gradient as well as a larger number of vacant active sites on the surface of PPY-PANI@RHA composites. ${ }^{16,39}$ Subsequently, the adsorption process attained equilibrium as indicated by unchanged $\mathrm{Cr}(\mathrm{vI})$ ion adsorption from aqueous solutions. It is also noted that equilibrium values of \% $\mathrm{Cr}(\mathrm{vI})$ removed correspond to $\sim 97 \%$ (300 $\mathrm{min}), \sim 86 \%$ (480 $\mathrm{min})$, and $\sim 80 \%$ (480 $\mathrm{min}$ ) for the $\mathrm{Cr}(\mathrm{vI})$ concentrations of 50,75 , and $100 \mathrm{mg} \mathrm{L}^{-1}$, respectively. Furthermore, the results also indicate that the increase of adsorbate concentration (50 to $100 \mathrm{mg} \mathrm{L}^{-1}$ ) reduced the removal efficiency of $\mathrm{Cr}(\mathrm{vI})$ under the same experimental conditions. This could be attributed to the active sites present on the surfaces of PPY-PANI@RHA being saturated by the $\mathrm{Cr}(\mathrm{VI})$ ions with an increase of adsorbate concentrations as the adsorbent dose is fixed. ${ }^{87}$

\subsection{Sorption kinetics study}

The kinetics of $\mathrm{Cr}(\mathrm{vI})$ ion adsorption on PPY-PANI@RHA has been investigated by fitting the experimental data based on the effect of contact time into the pseudo-first-order, pseudosecond-order, Elovich, intraparticle diffusion, and Boyed kinetics models as described in Table S1 (ESI $\dagger$ ). Fig. 5(b-f) accordingly show the effect of the adsorption rate of $\mathrm{Cr}(\mathrm{vI})$ based on different kinetic models corresponding to the initial $\mathrm{Cr}(\mathrm{vI})$ concentrations of 50,75 , and $100 \mathrm{mg} \mathrm{L}^{-1}$, respectively. Table S2 (ESI $\dagger$ ) records the kinetic parameters and statistical values for $\mathrm{Cr}(\mathrm{vI})$ adsorption on PPY-PANI@RHA related to different models corresponding to 50,75 , and $100 \mathrm{mg} \mathrm{L}^{-1}$ concentrations of $\mathrm{Cr}(\mathrm{vI})$ in aqueous solution. The higher correlation coefficient $\left(R^{2}\right)$ values and lower root mean square error (RMSE) values clearly demonstrated the better fitting of the experimental data in the Elovich model. In all probability, the chemisorption process played a significant role in the adsorption of $\mathrm{Cr}(\mathrm{vI})$ ions on the surface functional groups present in PPY-PANI@RHA. $^{88}$

The Webber-Morris intraparticle diffusion model has also been used to study the rate defining steps in the adsorption process of $\mathrm{Cr}(\mathrm{vI})$ ions on PPY-PANI@RHA, and the corresponding details are described in Table S1 (ESI $\dagger$ ). The variation of $q_{t}$ versus $t^{0.5}$ plots in Fig. 5(e) is found to be non-linear, comprising two different slopes with none of these passing through the origin that suggested the sorption process to be controlled by more than one mechanism such as intraparticle/ film diffusion. ${ }^{39,89}$ The initial steeper portion in the plot leads to the rapid extraction of $\mathrm{Cr}(\mathrm{vI})$ by PPY-PANI@RHA, mainly followed by surface/film diffusion. Subsequently, the gradual slope indicated a slow adsorption rate and is ascribed to the pore or intra-particle diffusion. ${ }^{10,90}$

Fig. 5(f) displays the Boyed plots corresponding to the adsorption of $\mathrm{Cr}(\mathrm{VI})$ ions for the initial $\mathrm{Cr}(\mathrm{vI})$ concentrations of 50,75 , and $100 \mathrm{mg} \mathrm{L}^{-1}$ on PPY-PANI@RHA in order to confirm the rate-limiting steps. These plots were found to be without passing through the origin in all the three $\mathrm{Cr}(\mathrm{vI})$ initial concentrations. These suggested external mass transfer (film diffusion) as the rate-determining step in the adsorption of Cr(vi) on PPY-PANI@RHA. ${ }^{16,89,91}$ However, the higher co-relation 

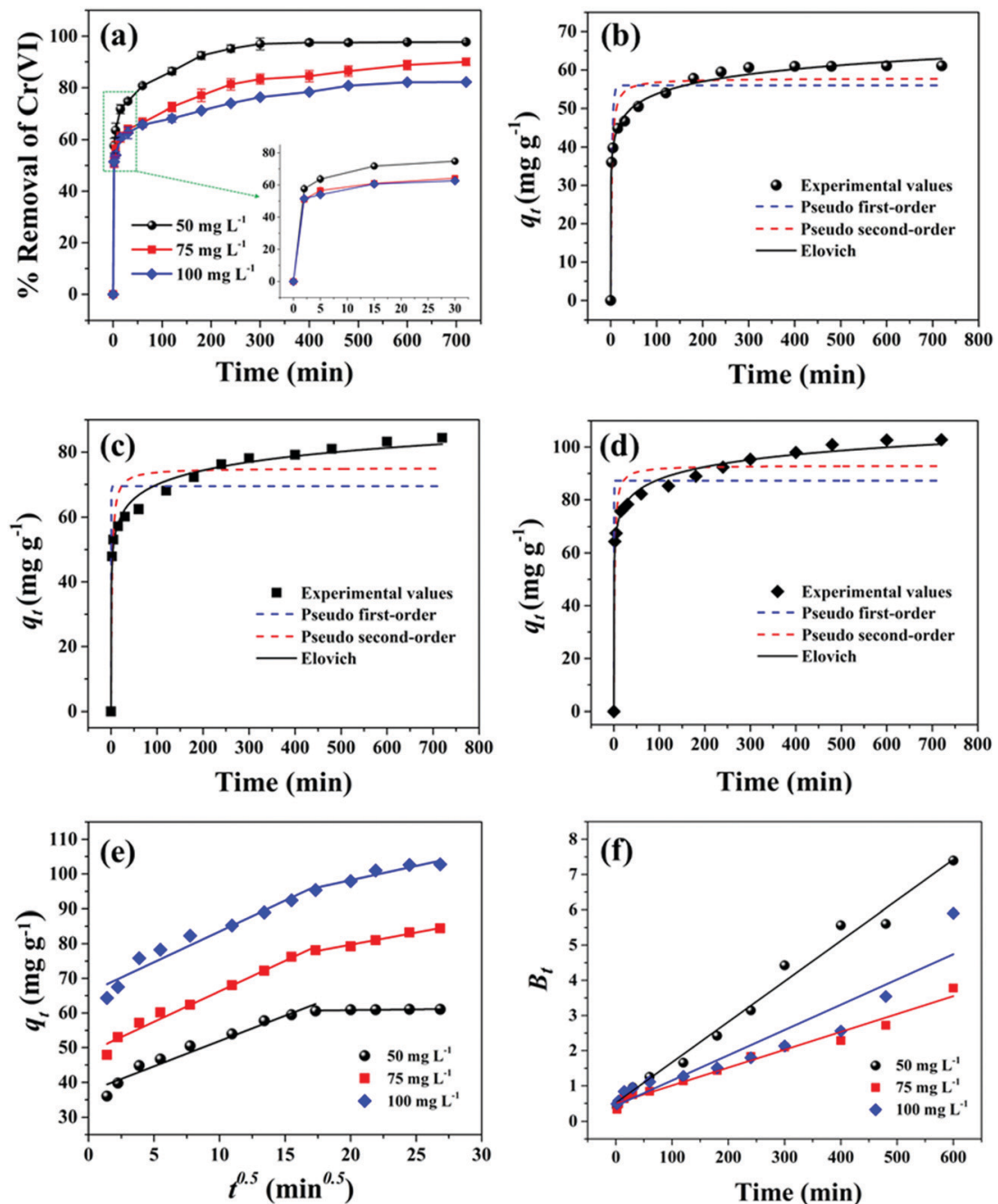

Fig. 5 (a) Effect of contact time on Cr(vI) adsorption using PPY-PANI@RHA nanocomposites at three different initial Cr(vI) concentrations of 50, 75, and $100 \mathrm{mg} \mathrm{L}^{-1}$; Experimental data fitted in pseudo-first-order, pseudo-second-order and Elovich kinetic models at initial $\mathrm{Cr}(\mathrm{VI}) \mathrm{concentrations}$ of (b) $50 \mathrm{mg} \mathrm{L}^{-1}$, (c) $75 \mathrm{mg} \mathrm{L}^{-1}$, and (d) $100 \mathrm{mg} \mathrm{L}^{-1}$ for adsorption of Cr(vi) on PPY-PANI@RHA; kinetic data fitted to (e) the Weber-Morris intra-particle diffusion plot, (f) Boyd plot for adsorption of $\mathrm{Cr}(\mathrm{vI})$ on PPY-PANIaRHA(PPY-PANI@RHA dose: $0.8 \mathrm{~g} \mathrm{~L}^{-1}$; $\mathrm{pH} \sim 2$; agitation speed: $200 \mathrm{rpm}$; temperature: $303 \mathrm{~K}$ ).

coefficient values $\left(R^{2}\right)$ and lower root mean square error (RMSE) values, as inferred from Table S2 (ESI $\dagger$ ), for the three different initial $\mathrm{Cr}(\mathrm{vI})$ concentrations suggest the following order in the fitting of kinetics models for the adsorption of $\mathrm{Cr}(\mathrm{vI})$ onto PPY-PANI@RHA: Elovich model $>$ PSO $>$ Boyed $>$ Intraparticle diffusion $>$ PFO.

\subsection{Sorption isotherm study}

The interaction between solid (adsorbent) and liquid phases (adsorbate species) has been used to study using the Langmuir, Freundlich, Dubinin-Radushkevich (D-R), and Temkin adsorption isotherms as provided in Table S3 (ESI $\dagger$ ). Fig. $6(\mathrm{a}-\mathrm{c})$ show the fitting of experimental data in the form of adsorption capacity of the adsorbent at equilibrium $\left(q_{\mathrm{e}}\right)$ versus adsorbate concentration at equilibrium $\left(C_{\mathrm{e}}\right)$ for all these absorption isotherms at $293 \mathrm{~K}, 303 \mathrm{~K}$, and $313 \mathrm{~K}$ temperatures. Table S4 (ESI $\dagger$ ) provides the respective isotherm parameters for the adsorption of $\mathrm{Cr}(\mathrm{VI})$ on PPY-PANI@ RHA. The higher values of the correlation coefficient $\left(\mathrm{R}^{2} \sim 0.99\right)$ corresponding to the Freundlich isotherm indicated its best-fitting at all the temperatures. It is also inferred that adsorption of $\mathrm{Cr}(\mathrm{vI})$ is not limited to the monolayer adsorption phenomenon and could be successfully applied to multilayer adsorption over the heterogeneous porous surface of PPY-PANI@RHA. ${ }^{59}$ However, according to Yang et al. and Boparai et al. the Freundlich isotherm equation could be applicable to both monolayer adsorption (chemisorption) as well as multilayer adsorption (van der Waals adsorption) processes..$^{90,92}$ The maximum adsorption capacities $\left(q_{\max }\right)$ of the PPY-PANI@RHA in $\mathrm{Cr}(\mathrm{v})$ adsorption were found to be 596.97, 769.15, and $914.17 \mathrm{mg} \mathrm{g}^{-1}$ at $293 \mathrm{~K}, 303 \mathrm{~K}$, and $313 \mathrm{~K}$, respectively. In addition, the isotherm parameter values $K_{\mathrm{F}}, q_{\mathrm{max}}$, and $b$ are increased with the increase of temperature inferred endothermic behavior of the adsorption process. ${ }^{6,85}$ The comparison of Langmuir maximum adsorption capacity $\left(q_{\max }\right)$ values for the removal of $\mathrm{Cr}(\mathrm{vI})$ from aqueous solutions by different adsorbents in the literature is summarized in Table S5 (ESI†). It is observed that the maximum $\mathrm{Cr}(\mathrm{VI})$ adsorption 

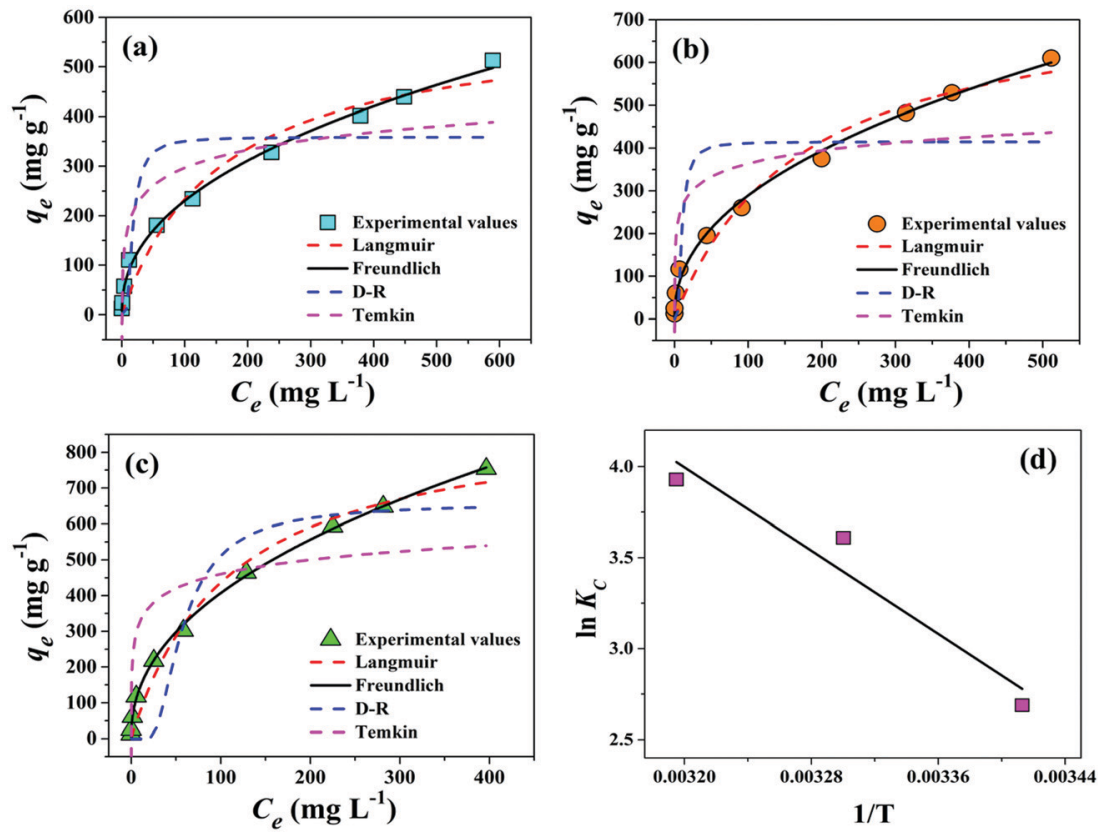

Fig. 6 Experimental data fitted in the Langmuir, Freundlich, D-R, Temkin isotherm model for Cr(vi) adsorption on the PPY-PANI@RHA nanocomposite at (a) $293 \mathrm{~K}$, (b) $303 \mathrm{~K}$, and (c) $313 \mathrm{~K}$ temperatures. (d) Van't Hoff plot of $\ln K_{\mathrm{C}}$ versus 1/T for $\mathrm{Cr}(\mathrm{VI})$ adsorption on PPY-PANI@RHA at a constant adsorbent dose of $0.8 \mathrm{~g} \mathrm{~L}^{-1}$ and $\mathrm{pH} 2$.

capacity of the PPY-PANI@RHA is significantly higher compared to those of other reported adsorbents. Therefore, PPY-PANI@RHA nanocomposites could be considered as a promising adsorbent for $\mathrm{Cr}(\mathrm{vI})$ removal due to their high adsorption capacity and simple and cost-effective synthesis.

\subsection{Thermodynamics study}

The thermodynamic parameters, for instance, the standard free surface energy change $\left(\Delta G^{0}, \mathrm{~kJ} \mathrm{~mol}^{-1}\right)$, change in standard enthalpy $\left(\Delta H^{0}, \mathrm{~kJ} \mathrm{~mol}^{-1}\right)$, and change in standard entropy $\left(\Delta S^{0}, \mathrm{~kJ} \mathrm{~mol}{ }^{-1} \mathrm{~K}^{-1}\right)$ help in understanding the nature of the adsorption of an adsorbate on an adsorbent at any given temperature. In view of this, $\Delta G^{0}, \Delta H^{0}$ and $\Delta S^{0}$ were calculated at three different temperatures $(293 \mathrm{~K}, 303 \mathrm{~K}$, and $313 \mathrm{~K}$ ) for the adsorption of $\mathrm{Cr}(\mathrm{vI})$ on PPY-PANI@RHA with a fixed concentration $\left(50 \mathrm{mg} \mathrm{L}^{-1}\right)$ of initial $\mathrm{Cr}(\mathrm{VI})$ solution and adsorbent dose $\left(0.8 \mathrm{~g} \mathrm{~L}^{-1}\right)$ according to the following equations:

$$
\begin{gathered}
\Delta G^{0}=-R T \ln K_{\mathrm{C}} \\
\ln K_{\mathrm{C}}=\frac{-\Delta H^{0}}{R T}+\frac{\Delta S^{0}}{R}
\end{gathered}
$$

where the temperature is indicated as $T$ in Kelvin, $R$ denotes the universal gas constant $\left(8.314 \mathrm{~J} \mathrm{~mol}^{-1} \mathrm{~K}^{-1}\right)$, and $\Delta H^{0}\left(\mathrm{~kJ} \mathrm{~mol}^{-1}\right)$ and $\Delta S^{0}\left(\mathrm{~kJ} \mathrm{~mol}^{-1} \mathrm{~K}^{-1}\right)$ were estimated from the slope and intercept of the linear Van't Hoff plot of $\ln K_{\mathrm{C}}$ versus $1 / T$ displayed in Fig. 6(d). The equilibrium constant $K_{\mathrm{C}}$ could be calculated at respective temperatures using the relationship: $K_{\mathrm{C}}=q_{\mathrm{e}} / C_{\mathrm{e}}$, where $q_{\mathrm{e}}$ and $C_{\mathrm{e}}$ are the amounts of adsorbed $\mathrm{Cr}(\mathrm{vI})$ ions on the adsorbent surface at equilibrium $\left(\mathrm{mg} \mathrm{\textrm {g } ^ { - 1 } )}\right.$ and the $\mathrm{Cr}(\mathrm{vI})$ concentration left in the solution after adsorption at equilibrium $\left(\mathrm{mg} \mathrm{L}^{-1}\right)$, respectively.,91,93 The values of temperature-dependent thermodynamic parameters were calculated, and the corresponding findings are displayed in Table S6 (ESI $\dagger)$. The positive value of $\Delta H^{0}\left(47.53 \mathrm{~kJ} \mathrm{~mol}^{-1}\right)$ suggests that the adsorption process is endothermic, and chemisorption prevails. ${ }^{6,50}$ Similarly, the positive value of $\Delta S^{0}$ (0.19 $\mathrm{kJ} \mathrm{mol}^{-1} \mathrm{~K}^{-1}$ ) suggested an increase in disorder at the adsorbate-adsorbent phase interaction at the time of $\mathrm{Cr}(\mathrm{vI})$ adsorption due to structural changes in the adsorbents. ${ }^{6,10}$ The $\Delta G^{0}$ values for the adsorption process were calculated at all three temperatures using the following thermodynamic relationship:

$$
\Delta G^{0}=\Delta H^{0}-T \Delta S^{0}
$$

The negative values of $\Delta G^{0}$ in Table S6 (ESI $\dagger$ ) suggested that the adsorption of $\mathrm{Cr}(\mathrm{vI})$ on PPY-PANI@RHA is found to be a spontaneous process. ${ }^{69}$

\subsection{Co-existing ion study}

Industrial wastewater consists of a variety of other co-existing ions (cations and anions) along with $\mathrm{Cr}(\mathrm{vI})$ interference in the adsorption processes. $^{6}$ In general, co-cations interfere with the positively charged adsorbates, and co-anions interfere with the negatively charged adsorbates. Therefore, the effect of other co-ions (cations: $\mathrm{Ca}^{2+}, \mathrm{Na}^{+}$, and $\mathrm{Mg}^{2+}$; anions: $\mathrm{Cl}^{-}, \mathrm{HCO}_{3}{ }^{2-}$, $\mathrm{SO}_{4}{ }^{2-}, \mathrm{NO}_{3}{ }^{-}$, and $\mathrm{PO}_{4}{ }^{3-}$ ) on $\mathrm{Cr}(\mathrm{vI})$ ion adsorption using PPY-PANI@RHA was studied, and the corresponding findings are graphically represented in Fig. 7(a) and (b). The experiment was conducted by adding different electrolytes such as $\mathrm{NaNO}_{3}$, $\mathrm{Mg}\left(\mathrm{NO}_{3}\right)_{2} \cdot 6 \mathrm{H}_{2} \mathrm{O}, \mathrm{NaCl}, \mathrm{Al}\left(\mathrm{NO}_{3}\right)_{3} \cdot 9 \mathrm{H}_{2} \mathrm{O}, \mathrm{Na}_{2} \mathrm{SO}_{4}$, and $\mathrm{Na}_{2} \mathrm{HPO}_{4}$. $2 \mathrm{H}_{2} \mathrm{O}$ by varying their concentrations (5 to $600 \mathrm{mg} \mathrm{L}^{-1}$ ) 


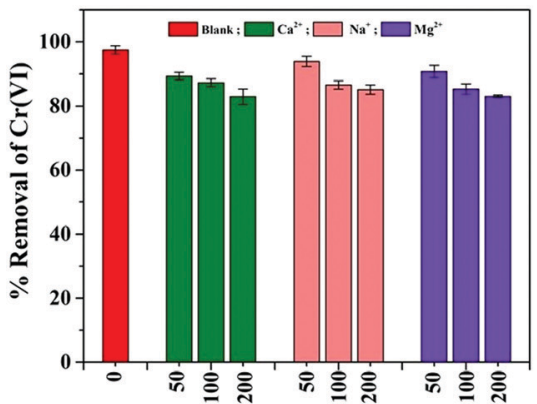

(a) Initial concentration of cation $\left(\mathrm{mg} \mathrm{L}^{-1}\right)$

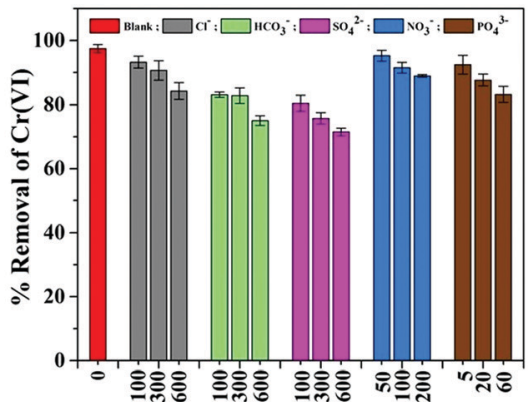

(b) Initial concentration of anion $\left(\mathrm{mg} \mathrm{L}^{-1}\right)$

Fig. 7 Effect of co-existing (a) cations, (b) anions on the removal of $\mathrm{Cr}(\mathrm{VI})$ by PPY-PANIaRHA. (Initial $\mathrm{Cr}(\mathrm{VI})$ concentration: 50 mg L ${ }^{-1}$; contact time: 300 min; agitation speed: 200 rpm; pH 2; temperature: 303 K).

separately in the aqueous solution containing a fixed $\mathrm{Cr}(\mathrm{vI})$ concentration $\left(50 \mathrm{mg} \mathrm{L}^{-1}\right)$ and at $\mathrm{pH} \sim 2$. Investigations show that more than $90 \% \mathrm{Cr}(\mathrm{vI})$ removal is achieved even in the presence of $\mathrm{Ca}^{2+}, \mathrm{Na}^{+}, \mathrm{Mg}^{2+}, \mathrm{NO}_{3}{ }^{-}$(initial concentration of $50 \mathrm{mg} \mathrm{L}^{-1}$ ) $\mathrm{Cl}^{-}$(initial concentration of $100 \mathrm{mg} \mathrm{L}^{-1}$ ), and $\mathrm{PO}_{4}{ }^{3-}$ (initial concentration $5 \mathrm{mg} \mathrm{L}^{-1}$ ) ions which implies the absence of competitive influence of these co-ions in $\mathrm{Cr}(\mathrm{VI})$ adsorption at low concentrations. ${ }^{18}$ However, \% removal of $\mathrm{Cr}(\mathrm{vI})$ slightly decreased to around $85 \%$ with the increase of the initial concentration of $\mathrm{Ca}^{2+}, \mathrm{Na}^{+}, \mathrm{Mg}^{2+}, \mathrm{Cl}^{-}, \mathrm{NO}_{3}{ }^{-}$and $\mathrm{PO}_{4}{ }^{3-}$, respectively, as displayed in Fig. 7. In all probability, the removal of $\mathrm{Cr}(\mathrm{vI})$ is not significantly altered due to the repulsion between positively charged co-ions and the protonated adsorbent surface in acidic $\mathrm{pH}^{6}$

In contrast, the $\%$ removal of $\mathrm{Cr}(\mathrm{vI})$ decreased from $\sim 83$ to $75 \%$ and 80 to $71 \%$ in the presence of $\mathrm{HCO}_{3}{ }^{-}$and $\mathrm{SO}_{4}{ }^{2-}$ for the initial concentration ranging from 100 to $600 \mathrm{mg} \mathrm{L}^{-1}$, respectively. These findings also suggested that interference is directly proportional to the size of the cations or solubility of the electrolytes and is inversely proportional to the charge on the cations and bond dissociation energy of the electrolytes. ${ }^{17,59}$ Our results also indicated that $\mathrm{Cr}(\mathrm{vI})$ adsorption has significantly interfered in the presence of a high concentration of anions $\left(\mathrm{Cl}^{-}\right.$, $\mathrm{PO}_{4}{ }^{3-}, \mathrm{HCO}_{3}{ }^{-}$and $\mathrm{SO}_{4}{ }^{2-}$ ) due to competitive adsorption with $\mathrm{Cr}(\mathrm{vI})$ ions $\left(\mathrm{HCrO}_{4}{ }^{-}\right)$on PPY-PANI@RHA. ${ }^{6,35}$ The results also indicated that higher the concentration of co-existing ions, greater the interference on the adsorption of $\mathrm{Cr}(\mathrm{VI})$ ions on PPY-PANI@RHA due to the high competition for adsorbent sites. These studies indicate the possible successful application of PPY-PANI@RHA in the removal of $\mathrm{Cr}(\mathrm{vI})$ from industrial wastewater as well.

\subsection{Proposed adsorption mechanism}

The possible $\mathrm{Cr}(\mathrm{vI})$ adsorption mechanism by the PPY-PANI@ RHA adsorbent could be described as depicted in Fig. 8. It is a well-established fact that $\mathrm{pH}$ plays a very significant role in controlling the adsorption mechanism. ${ }^{38,39}$ As described earlier in a $\mathrm{pH}$ study, the predominated $\mathrm{Cr}(\mathrm{vI})$ species is generally $\mathrm{HCrO}_{4}{ }^{-}$at lower $\mathrm{pH}^{6}{ }^{6,7}$ Therefore, it is anticipated that highly protonated polymeric chains in acidic medium could be accounted for the ion-exchange between doped $\mathrm{Cl}^{-}$ions present on the surface of the adsorbent with the $\mathrm{HCrO}_{4}{ }^{-}$ions in the $\mathrm{Cr}(\mathrm{VI})$ solution. ${ }^{6,10,85}$ Besides, strong electrostatic attraction due to the presence of a highly protonated PPY-PANI@RHA surface with positively charged amine functional groups (-NH-, $-\mathrm{N}<,-\mathrm{NH}_{2}$ ) and $\mathrm{HCrO}_{4}{ }^{-}$species, as well as the contribution of the porous structure of PPY-PANI@RHA, could also facilitate the enhanced removal of $\mathrm{Cr}(\mathrm{VI})$ from aqueous solutions. ${ }^{40,50}$ Alternatively, the possibility of $\mathrm{Cr}(\mathrm{VI})$ reduction to $\mathrm{Cr}(\mathrm{III})$ in the acidic environment due to the high redox potential (range: 1.33$1.38 \mathrm{~V}$ ) also could not be ruled out. ${ }^{7}$

\subsection{Desorption and reusability study}

The desorption of hexavalent chromium is an essential aspect of the regeneration of spent adsorbent for industrial applications. In view of this, $\mathrm{Cr}(\mathrm{vI})$ desorption was performed by treating the spent adsorbent (PPY-PANI@RHA-Cr(vI)) with 0.01-1 M NaOH solution, which accelerates the deprotonation of $-\mathrm{NH}_{3}{ }^{+}$groups

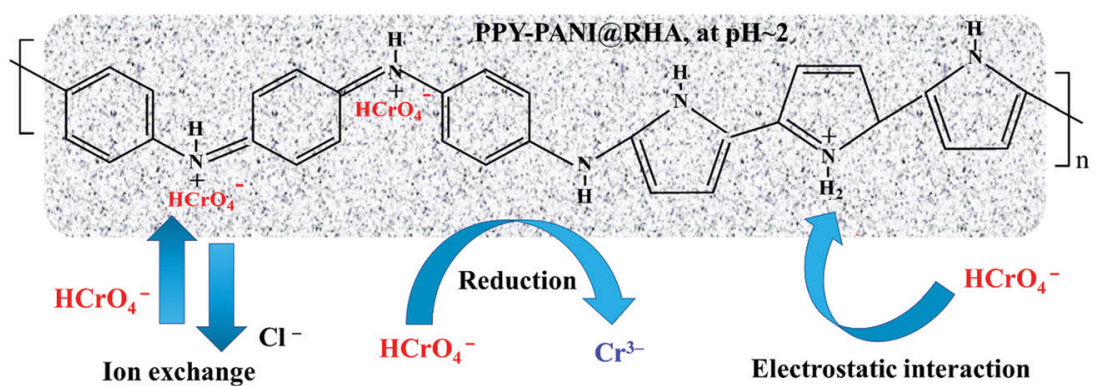

Fig. 8 Schematic representation of possible $\mathrm{Cr}(\mathrm{VI})$ adsorption by PPY-PANICRHA. 


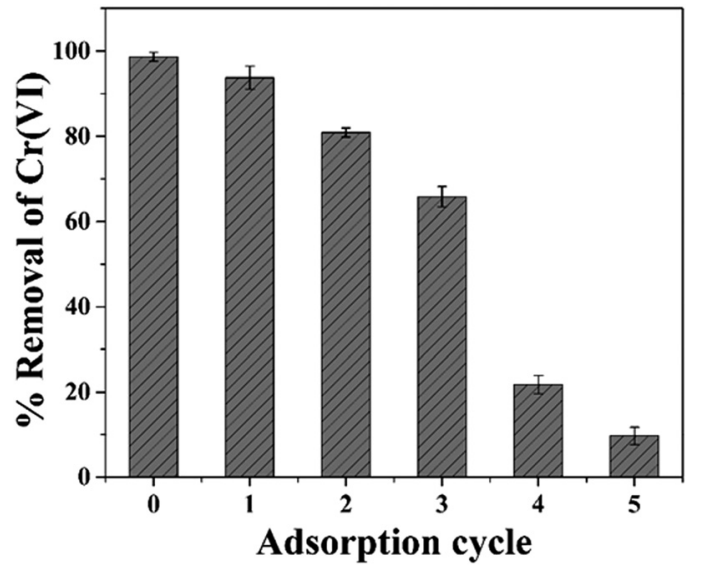

Fig. 9 Reusability capacity of PPY-PANI@RHA up to five cycles for the removal of $\mathrm{Cr}(\mathrm{VI})$ (Initial $\mathrm{Cr}(\mathrm{VI})$ concentration: $50 \mathrm{mg} \mathrm{L}^{-1}$; regenerated PPY-PANI@RHA dose: $0.8 \mathrm{~g} \mathrm{~L}^{-1}$; contact time: $300 \mathrm{~min}$; agitation speed: 200 rpm; $\mathrm{pH} \sim 2$; temperature: $303 \mathrm{~K}$ ).

on the surface of PPY-PANI@RHA, resulting in the decrease of electrostatic attraction between these groups and $\mathrm{Cr}(\mathrm{vI})$ species $\left(\mathrm{HCrO}_{4}{ }^{-}\right){ }^{6,10,15}$ It was noted that desorption efficiency varied from $\sim 7.1 \%$ to $29.4 \%$, corresponding to $0.01,0.2,0.5$, and $1 \mathrm{M}$ $\mathrm{NaOH}$, as displayed in Fig. S4 (ESI $\dagger$ ). Such a low desorption efficiency of $\mathrm{Cr}(\mathrm{vI})$ could be ascribed to the reduction of $\mathrm{Cr}(\mathrm{vI})$ to $\mathrm{Cr}(\mathrm{III})$ species. ${ }^{10,47}$ Subsequently, the regenerated adsorbent was successfully subjected to adsorption of $\mathrm{Cr}(\mathrm{vI})$ for five desorption/ adsorption cycles, and the findings are displayed in Fig. 9. According to these findings, the removal efficiency in the first and second cycles corresponds to 94 and $80 \%$. However, in the 3rd cycle the $\mathrm{Cr}(\mathrm{vI})$ removal efficiency decreased to $\sim 65 \%$, followed by a continuous drastic reduction in the fourth and fifth cycles. The observed decrease in the $\mathrm{Cr}(\mathrm{vI})$ removal efficiency of the spent material is in all probability due to the disintegration/ deterioration of PPY-PANI in PPY-PANI@RHA composites. ${ }^{6}$ Alternatively, the rupture of the polymer chain by a repeated reaction of oxidation with highly oxidizing $\mathrm{Cr}(\mathrm{VI})$ species could decrease the mass sorption sites in the spent adsorbent, which could also be accounted for the decrease in the adsorption capacity of used PPY-PANI@RHA. ${ }^{37}$ Our findings demonstrated that spent PPY-PANI@RHA could be successfully reused up to three times with a high $\mathrm{Cr}(\mathrm{VI})$ removal efficiency in a sustainable manner.

\subsection{Removal of $\mathrm{Cr}(\mathrm{vr})$ ions from real industrial effluent samples}

A $\mathrm{Cr}(\mathrm{vI})$ bearing wastewater sample was collected from the common effluent treatment plant (CETP), Kolkata leather complex (West Bengal, India), and subjected to removal of Cr(vi) using PPY-PANI@RHA. The amount of chromium in the tannery effluent varied depending on the leather processing events. The $\mathrm{Cr}(\mathrm{vI})$ concentration was found to be $\sim 51.33 \mathrm{mg} \mathrm{L}^{-1}$. The characterization of the collected wastewater sample, including TSS, TDS, $\mathrm{BOD}_{5}$, COD, and other co-existing parameters, is provided in Table S7 (ESI $\dagger$ ). Fig. S5(a) (ESI $\dagger$ ) shows the rate of \% removal and adsorption capacity of $\mathrm{Cr}(\mathrm{vI})$ with the variation of
PPY-PANI@RHA doses ( 0.5 to $5 \mathrm{~g} \mathrm{~L}^{-1}$ ) at a fixed time (300 min) and by keeping other parameters the same. The result shows that with the increase of adsorbent dose, the \% removal of $\mathrm{Cr}(\mathrm{vI})$ from the wastewater sample is increased, and the corresponding adsorption capacity is decreased. Furthermore, experiments were conducted to study the \% removal of $\mathrm{Cr}(\mathrm{vI})$ from the wastewater sample by varying the contact time ( 2 to $300 \mathrm{~min}$ ) at three different adsorbent doses of 1, 2.5, and $5 \mathrm{~g} \mathrm{~L} \mathrm{~L}^{-1}$, as displayed in Fig. S5(b) (ESI $\dagger$ ). Our finding shows that the $\mathrm{Cr}(\mathrm{vI})$ removal efficiency is improved with the increase of adsorbent dose, and at $300 \mathrm{~min}$, it achieved $\sim 63,80$, and $84 \%$ of $\mathrm{Cr}(\mathrm{vI})$ removal corresponding to $1,2.5$, and $5 \mathrm{~g} \mathrm{~L}^{-1}$ of adsorbent dose, respectively. These findings demonstrated that PPY-PANI@RHA could efficiently remove the $\mathrm{Cr}(\mathrm{vI})$ ions from the highly polluted tannery wastewater.

\section{Conclusions}

PPY-PANI@RHA nanocomposites were prepared by oxidative polymerization of pyrrole and aniline on the surface of rice husk ash and characterized by XRD, FTIR, Raman spectroscopy, FE-SEM, HR-TEM, BET surface area analysis, porosity and pore volume measurements. Subsequently, PPY-PANI@RHA was used as an adsorbent to study the effect of adsorbate initial concentration, adsorbent dose, $\mathrm{pH}$ of the aqueous solution, and contact time on the removal of $\mathrm{Cr}(\mathrm{vI})$ from contaminated water in the batch study. Our findings showed PPY-PANI@RHA to be very effective as an adsorbent exhibiting about $~ 98 \%$ removal of $\mathrm{Cr}(\mathrm{vI})$ from contaminated water $(\mathrm{pH} \sim 2)$, corresponding to an initial $\mathrm{Cr}(\mathrm{vI})$ concentration of $50 \mathrm{mg} \mathrm{L}^{-1}$ and an adsorbent dose of $0.8 \mathrm{~g} \mathrm{~L}^{-1}$. The adsorption of $\mathrm{Cr}(\mathrm{vI})$ on PPY-PANI@RHA is well described by the Elovich kinetics as well as the Freundlich isotherm model. Additionally, the thermodynamic study demonstrates the nature of $\operatorname{Cr}(\mathrm{vI})$ adsorption phenomenon is spontaneous and endothermic. Furthermore, the experiment shows that the removal efficiency of $\mathrm{Cr}(\mathrm{vI}) \mathrm{using}$ PPY-PANI@RHA is not significantly altered in the presence of moderate concentrations of $\mathrm{Ca}^{2+}, \mathrm{Na}^{+}, \mathrm{Mg}^{2+}$, and $\mathrm{Cl}^{-}, \mathrm{NO}_{3}{ }^{-}$, $\mathrm{PO}_{4}{ }^{3-}$ co-existing ions. Desorption and regeneration studies have also been carried out on the reusability of the PPY-PANI@ RHA composite for several times. Finally, our investigations successfully demonstrated the suitability of the prepared PPY-PANI@RHA adsorbent in removing Cr(vi) ions from the highly polluted raw tannery wastewater sample.

\section{Conflicts of interest}

There are no conflicts to declare.

\section{Acknowledgements}

S. D. is thankful to the Indian Institute of Technology Kharagpur for providing the fellowship. The authors are also grateful to the authority of the CETP, Kolkata leather complex, West Bengal, India, for helping during $\mathrm{Cr}(\mathrm{vI})$ contaminated wastewater sample collection. 


\section{Notes and references}

1 C. B. Godiya, L. A. Martins Ruotolo and W. Cai, J. Mater. Chem. A, 2020, 8, 21585-21612.

2 A. P. Panda, P. Rout, K. K. Jena, S. M. Alhassan, S. A. Kumar, U. Jha, R. K. Dey and S. K. Swain, J. Mater. Chem. A, 2019, 7, 9933-9947.

3 A. P. Panda, P. Rout, S. A. Kumar, U. Jha and S. K. Swain, J. Mater. Chem. A, 2020, 8, 4318-4333.

4 Z. Ren, D. Kong, K. Wang and W. Zhang, J. Mater. Chem. A, 2014, 2, 17952-17961.

5 K. Perikamana, I. M. Sasidharan Pillai, A. K. Gupta and A. Sulaiman, J. Environ. Sci. Health, Part A: Toxic/Hazard. Subst. Environ. Eng., 2013, 48, 67-78.

6 Y. Xu, J. Chen, R. Chen, P. Yu, S. Guo and X. Wang, Water Res., 2019, 160, 148-157.

7 M. Sharma, M. Joshi, S. Nigam, S. Shree, D. K. Avasthi, R. Adelung, S. K. Srivastava and Y. Kumar Mishra, Chem. Eng. J., 2019, 358, 540-551.

8 M. Sharma, M. Poddar, Y. Gupta, S. Nigam, D. K. Avasthi, R. Adelung, R. Abolhassani, J. Fiutowski, M. Joshi and Y. K. Mishra, Mater. Today Chem., 2020, 17, 100336.

9 P. C. Grevatt, US Environmental Protection Agency, Washington DC, 1998.

10 M. Bhaumik, A. Maity, V. V. Srinivasu and M. S. Onyango, Chem. Eng. J., 2012, 181-182, 323-333.

11 B. Qiu, H. Gu, X. Yan, J. Guo, Y. Wang, D. Sun, Q. Wang, M. Khan, X. Zhang, B. L. Weeks, D. P. Young, Z. Guo and S. Wei, J. Mater. Chem. A, 2014, 2, 17454-17462.

12 A. Zhitkovich, Chem. Res. Toxicol., 2011, 24, 1617-1629.

13 Guidelines for Drinking-Water Quality, World Health Organization (WHO), Geneva, 3rd edn, 2006.

14 EPA (Environmental Protection Agency), Environmental Pollution Control Alternatives, EPA/625/5-90/025, EPA/625/ 4-89/023, Cincinnati, US, 1990.

15 V. E. Pakade, N. T. Tavengwa and L. M. Madikizela, $R S C$ Adv., 2019, 9, 26142-26164.

16 J. Acharya, J. N. Sahu, B. K. Sahoo, C. R. Mohanty and B. C. Meikap, Chem. Eng. J., 2009, 150, 25-39.

17 M. Ghosh and S. Mishra, Arabian J. Sci. Eng., 2017, 42, 4391-4400.

18 J. Hu, G. Chen and I. M. C. Lo, Water Res., 2005, 39, 4528-4536.

19 L. Zhang, W. Xia, X. Liu and W. Zhang, J. Mater. Chem. A, 2015, 3, 331-340.

20 J. Huang, Y. Li, Y. Cao, F. Peng, Y. Cao, Q. Shao, H. Liu and Z. Guo, J. Mater. Chem. A, 2018, 6, 13062-13074.

21 Y. Li, Q. Shen, R. Guan, J. Xue, X. Liu, H. Jia, B. Xu and Y. Wu, J. Mater. Chem. C, 2020, 8, 1025-1040.

22 K. Manna and S. K. Srivastava, ACS Sustainable Chem. Eng., 2017, 5, 10710-10721.

23 B. Butoi, A. Groza, P. Dinca, A. Balan and V. Barna, Polymers, 2017, 9, 732.

24 P. Xie, Y. Li, Q. Hou, K. Sui, C. Liu, X. Fu, J. Zhang, V. Murugadoss, J. Fan and Y. Wang, et al., J. Mater. Chem. C, 2020, 8, 3029-3039.

25 R. Panigrahi and S. K. Srivastava, Sci. Rep., 2015, 5, 7638.
26 V. Elayappan, V. Murugadoss, Z. Fei, P. J. Dyson and S. Angaiah, Eng. Sci., 2020, 10, 78-84.

27 H. Gu, H. Zhang, C. Gao, C. Liang, J. Gu and Z. Guo, ES Mater. Manuf., 2018, 1, 3-12.

28 R. V. Ingle, S. F. Shaikh, P. K. Bhujbal, H. M. Pathan and V. A. Tabhane, ES Mater. Manuf., 2020, 8, 54-59.

29 S. Li, A. Jasim, W. Zhao, L. Fu, M. W. Ullah, Z. Shi and G. Yang, ES Mater. Manuf., 2018, 1, 41-49.

30 J. Zhao, Z. Li, J. Wang, Q. Li and X. Wang, J. Mater. Chem. A, 2015, 3, 15124-15132.

31 W. Sun, W. Zhang, H. Li, Q. Su, P. Zhang and L. Chen, RSC Adv., 2020, 10, 8790-8799.

32 R. Zhang, H. Ma and B. Wang, Ind. Eng. Chem. Res., 2010, 49, 9998-10004.

33 H. Eisazadeh, J. Appl. Polym. Sci., 2007, 104, 1964-1967.

34 X. Han, L. Gai, H. Jiang, L. Zhao, H. Liu and W. Zhang, Synth. Met., 2013, 171, 1-6.

35 M. Janmohammadi, M. Baghdadi, T. M. Adyel and N. Mehrdadi, Sci. Total Environ., 2021, 752, 141850.

36 J. Wang, K. Zhang and L. Zhao, Chem. Eng. J., 2014, 239, 123-131.

37 K. K. Krishnani, S. Srinives, B. C. Mohapatra, V. M. Boddu, J. Hao, X. Meng and A. Mulchandani, J. Hazard. Mater., 2013, 252-253, 99-106.

38 U. O. Aigbe, R. Das, W. H. Ho, V. Srinivasu and A. Maity, Sep. Purif. Technol., 2018, 194, 377-387.

39 S. Dutta, K. Manna, S. K. Srivastava, A. K. Gupta and M. K. Yadav, Sci. Rep., 2020, 10, 4982.

40 S. Deng and Y. P. Ting, Environ. Sci. Technol., 2005, 39, 8490-8496.

41 N. A. S. A. Reyad, HBRC J., 2017, 13, 297-301.

42 K. Gong, S. Guo, Y. Zhao, Q. Hu, H. Liu, D. Sun, M. Li, B. Qiu and Z. Guo, J. Mater. Chem. A, 2018, 6, 16824-16832.

43 V. D. Thao, B. L. Giang and T. V. Thu, RSC Adv., 2019, 9, 5445-5452.

44 M. Ghorbani and H. Eisazadeh, Composites, Part B, 2013, 45, 1-7. 45 A. Andreatta, A. J. Heeger and P. Smith, Polym. Commun., 1990, 31, 275.

46 A. Nazzal and G. Street, J. Chem. Soc., Chem. Commun., 1985, 375-376.

47 R. Karthik and S. Meenakshi, Desalin. Water Treat., 2015, 56, 1587-1600.

48 M. Bhaumik, V. K. Gupta and A. Maity, J. Environ. Chem. Eng., 2018, 6, 2514-2527.

49 J. Chen, X. Hong, Y. Zhao, Y. Xia, D. Li and Q. Zhang, J. Mater. Sci., 2013, 48, 7708-7717.

50 M. Chigondo, H. K. Paumo, M. Bhaumik, K. Pillay and A. Maity, J. Mol. Liq., 2019, 275, 778-791.

51 R. Karthik and S. Meenakshi, Int. J. Biol. Macromol., 2015, 72, 711-717.

52 A. G. Yavuz, E. Dincturk-Atalay, A. Uygun, F. Gode and E. Aslan, Desalination, 2011, 279, 325-331.

53 S. Sahu, P. Kar, N. Bishoyi, L. Mallik and R. K. Patel, J. Chem. Eng. Data, 2019, 64, 4357-4368.

54 W. Fang, X. Jiang, H. Luo and J. Geng, Chemosphere, 2018, 197, 594-602. 
55 G. Dognani, P. Hadi, H. Ma, F. C. Cabrera, A. E. Job, D. L. S. Agostini and B. S. Hsiao, Chem. Eng. J., 2019, 372, 341-351.

56 K. Swarnalakshmi, P. Chinnaiyan, S. Nivetha and A. S. Nair, Mater. Today: Proc, 2018, 5, 24248-24257.

57 H. D. da Rocha, E. S. Reis, G. P. Ratkovski, R. J. da Silva, F. D. S. Gorza, G. C. Pedro and C. P. de Melo, J. Taiwan Inst. Chem. Eng., 2020, 110, 8-20.

58 M. Ghorbani, M. S. Lashkenari and H. Eisazadeh, Synth. Met., 2011, 161, 1430-1433.

59 X. Huang, G. Dognani, P. Hadi, M. Yang, A. E. Job and B. S. Hsiao, ACS Sustainable Chem. Eng., 2020, 8, 4734-4744.

60 M. Ahmaruzzaman and V. K. Gupta, Ind. Eng. Chem. Res., 2011, 50, 13589-13613.

61 F. Ghorbani, A. M. Sanati and M. Maleki, Environ. Stud. Persian Gulf, 2015, 2, 56-65.

62 S. K. Shukla, in Green Materials for Wastewater Treatment, ed. Mu. Naushad and E. Lichtfouse, Springer International Publishing, Cham, 2020, vol. 38, pp. 131-148.

63 K. Dutta and S. K. De, Phys. Lett. A, 2007, 361, 141-145.

64 X. Li, N. Dai, G. Wang and X. Song, J. Appl. Polym. Sci., 2008, 107, 403-408.

65 T. A. Tikish, A. Kumar and J. Y. Kim, Adv. Mater. Sci. Eng., 2018, 1-5.

66 F. Fusalba and D. Bélanger, J. Phys. Chem. B, 1999, 103, 9044-9054.

67 S. Balasubramanian and V. Pugalenthi, Talanta, 1999, 50, 457-467.

68 R. Khan, A. Jabbar, I. Ahmad, W. Khan, A. N. Khan and J. Mirza, Constr. Build. Mater., 2012, 30, 360-365.

69 M. Bhaumik, A. Maity, V. V. Srinivasu and M. S. Onyango, J. Hazard. Mater., 2011, 190, 381-390.

70 K. He, C. Qin, Q. Wen, C. Wang, B. Wang, S. Yu, C. Hao and K. Chen, J. Appl. Polym. Sci., 2018, 135, 6289.

71 N. Malek and A. M. Yusof, Malays. J. Anal. Sci., 2007, 11, 76-83.

72 P. Prabunathan, K. Sethuraman and M. Alagar, RSC Adv., 2014, 4, 47726-47734.

73 M. Ghorbani and H. Eisazadeh, Synth. Met., 2012, 162, 1429-1433.
74 V. Vickackaite and V. Ciuvasovaite, Cent. Eur. J. Chem., 2007, 5, 727-738.

75 H.-H. Wu, C.-W. Chang, D. Lu, K. Maeda and C. Hu, ACS Appl. Mater. Interfaces, 2019, 11, 35702-35712.

76 A. Yelil Arasi, J. Juliet Latha Jeyakumari, B. Sundaresan, V. Dhanalakshmi and R. Anbarasan, Spectrochim. Acta, Part A, 2009, 74, 1229-1234.

77 C. Merlini, B. S. Rosa, D. Müller, L. G. Ecco, S. D. A. S. Ramôa and G. M. O. Barra, Polym. Test., 2012, 31, 971-977.

78 S. Weng, J. Zhou and Z. Lin, Synth. Met., 2010, 160, 1136-1142.

79 H. Bai, Q. Chen, C. Li, C. Lu and G. Shi, Polymer, 2007, 48, 4015-4020.

80 Y.-C. Liu and B.-J. Hwang, Synth. Met., 2000, 113, 203-207.

81 P. A. Herrera Herrera, N. C. Santana and J. A. Martinez, ECS Trans., 2018, 84, 243-256.

82 M. Deng, G. Zhang, X. Peng, J. Lin, X. Pei and R. Huang, Mater. Lett., 2016, 163, 36-38.

83 Z. Ren, X. Xu, X. Wang, B. Gao, Q. Yue, W. Song, L. Zhang and H. Wang, J. Colloid Interface Sci., 2016, 468, 313-323.

84 A. S. Hammad, H. Noby, M. F. Elkady and A. H. El-Shazly, IOP Conf. Ser.: Mater. Sci. Eng., 2018, 290, 012001.

85 M. Bhaumik, S. Agarwal, V. K. Gupta and A. Maity, J. Colloid Interface Sci., 2016, 470, 257-267.

86 J. Lu, Z. Liu, Z. Wu, W. Liu and C. Yang, Sep. Purif. Technol., 2020, 237, 116346.

87 Y. Pang, G. Zeng, L. Tang, Y. Zhang, Y. Liu, X. Lei, Z. Li, J. Zhang, Z. Liu and Y. Xiong, Chem. Eng. J., 2011, 175, 222-227.

88 F.-C. Wu, R.-L. Tseng and R.-S. Juang, Chem. Eng. J., 2009, 150, 366-373.

89 S. Nethaji, A. Sivasamy and A. B. Mandal, Int. J. Environ. Sci. Technol., 2013, 10, 231-242.

90 H. K. Boparai, M. Joseph and D. M. O'Carroll, J. Hazard. Mater., 2011, 186, 458-465.

91 L. Ai, M. Li and L. Li, J. Chem. Eng. Data, 2011, 56, 3475-3483.

92 C. Yang, J. Colloid Interface Sci., 1998, 208, 379-387.

93 E. Mekonnen, M. Yitbarek and T. R. Soreta, South Afr. J. Chem., 2015, 68, 45-52. 